\title{
LA CIUDAD ROMANA DE POLLENTIA: EL FORO *
}

\author{
POR \\ M. ORFILA PONS \\ Universidad de Granada \\ A. ARRIBAS PALAU \\ Universidad de Granada \\ M. A. CAU ONTIVEROS \\ University of Sheffield \\ Equip de Recerca Arqueometrica de la Universitat de Barcelona
}

\section{RESUMEN}

Revisión de las diversos períodos de ocupación del foro de Pollentia, desde sus inicios en el primer cuarto del siglo $\mathrm{I}$ a.C. hasta la época islámica, destacando las reformas documentadas para época alto imperial y las del siglo III d.C., con especial atención al recinto fortificado que se construyó en época tardía en el antiguo foro de la ciudad.

\section{SUMMARY}

This is the revision of the different periods of Pollentia's forum since the beginning of the first quarter of the $1 \mathrm{st}$. century BC until the Islamic period. We point out the documented reforms in the early Empire and also in the 3rd. century AD with special attention to the fortified precinct built in the late period over what had been the forum of the city.

\section{INTRODUCCIÓN}

Las Baleares, Mallorca y Menorca, fueron conquistadas en el año 123 a.C.' por un contingente militar romano dirigido por el cónsul Quinto Cecilio Metelo, el Baleárico. Una de las consecuencias palpables de esta conquista en la isla mayor fue la

\footnotetext{
* Queremos agradecer desde aquí la ayuda prestada a las personas que en estos últimos años han colaborado en las tareas de excavación del Foro de Pollentia: Esther Chávez, Mateu Riera, Jaume Cardell, Miquel Seguí, Maribel Mancilla, Julio Román y Toni Puig.

Las fuentes literarias hacen referencia a los problemas que causaban los piratas que habitaban estas islas (Estrabón 3,5,1; Floro 1,43; Orosio, 5,13,1; Tito Livio, libro LX). Los análisis históricos actuales llevan a plantear, además de la causa ya citada, el debate político sobre la Ley Agraria de C.S. Graco (Balil, 1965:310; Zucca, 1998:95), las cuestiones de tipo militar, la importancia de una vía marítima directa hacia Hispania o la económica, el potencial de riqueza de las tierras de las Baleares (Roldán, 1978:424-427). Además, Arribas (1983:6) se refiere a la problemática general de la política romana de expansión territorial.
}

fundación de dos importantes establecimientos urbanos: Palma y Pollentia ${ }^{2}$.

La localización concreta de Pollentia, cerca de la actual ciudad de Alcudia, quedó comprobada centurias atrás por las piezas arqueológicas halladas en unos terrenos conocidos bajo el topónimo de Campos de Santa Ana. En estos terrenos se hallaron, por poner algún ejemplo, tanto piezas epigráficas como monedas, o una cabeza de mármol de Augusto Velado (Arribas, 1983a). La ciudad está situada sobre un promontorio a 14 m.s.n.m., considerado como punto inicial de la península que divide las dos magníficas bahías de Alcudia y Pollensa al nordeste de Mallorca. Esta situación estratégica responde al control del territorio y de los movimientos marítimos de la zona ${ }^{3}$.

Las excavaciones desarrolladas durante gran parte de este siglo $\mathrm{xx}$ han permitido conocer barrios residenciales de la ciudad (fig. 1), como los identi-

2 Estrabón describe su ubicación $(3,5,1)$. Son citadas por Mela (2.124) como colonias y Plinio $(3,77)$ indica que eran oppida $c$. $R$. También son mencionadas Guium y Tucis (Plinio $3,77,78$ ) que disfrutaron sólo del ius Latii y el otro establecimiento citado, el de los Bocchorum, lo es como federado, cuyo étnico parece de raíz púnica (Plinio, 3,77; Mayer y Rodà, 1983). Es, junto a Guium y Tucis, la únicas comunidad indígena citada por las fuentes, y, curiosamente Bocchorum - a la que Plinio se refiere en pasado, como si ya no existiera- fue federada, como lo fue también Ebusus (Plinio, 3,76).

3 La prospección arqueológica de los entornos de la ciudad (Coll et alli, 1984: 128) muestra una organización territorial en la que se documentan diversos asentamientos rurales con funciones de villae, diecinueve de ellos sobre hábitat talayótico y doce de nueva planta, situados en su mayoría en las zonas llanas junto a tierras de cultivo. Se identifica también un programa defensivo basado en el establecimiento de puntos de observación en la zona costera de la península, de un total de siete puntos estratégicos de observación o defensa, seis en la zona peninsular, con un sistema de visualización mutuo que permitía transmitir cualquier señal desde la costa a la ciudad mediante su conexión al séptimo punto ubicado sobre un altozano desde el que se visualizan los restantes puntos y la ciudad, controlándose así perfectamente las entradas de las dos bahías. 


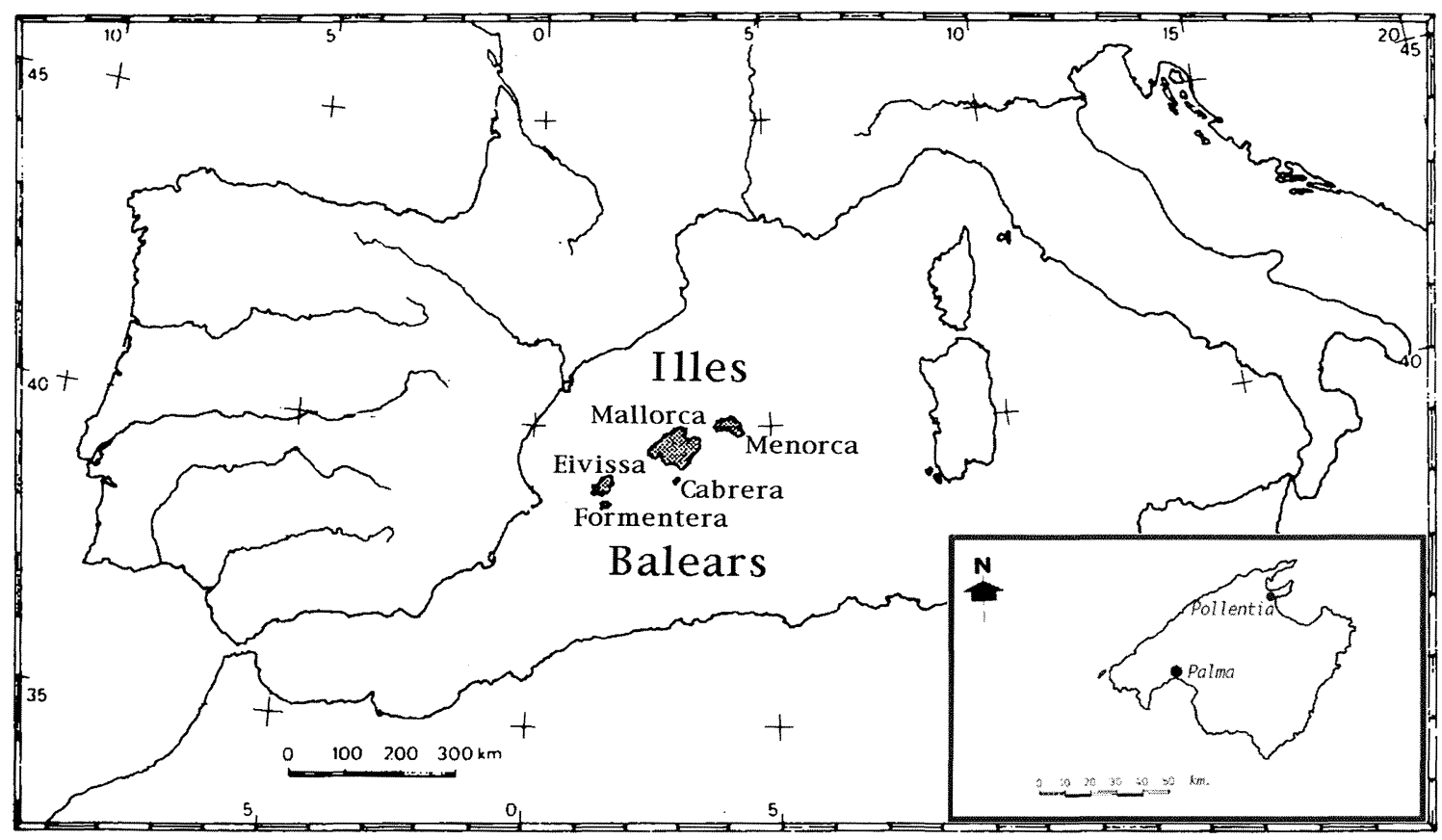

Fig. 1.-Mapa de ubicación de las islas Baleares en el Mediterráneo Occidental.

ficados en las fincas de Sa Portella (Arribas, Tarradell y Woods, 1973 y 1978), Ca'n Basser, Ca'n Viver, la Casa de Polymnia en Camp d'en França, Cán Pí, o los ubicados al oeste del Camino del Cementerio ${ }^{4}$. Se ha identificado además el teatro en Sa Solada (Amorós, Almagro, y Arribas, 1953) y el foro se localizó en la finca de Santa Ana de Ca'n Reiners (Arribas y Tarradell, 1987; Equip d'Excavacions de Pollentia 1994 a y b). Se conocen también dos estructuras defensivas, la de Sa Portella (Arribas, Tarradell y Woods, 1973, 1978) y la de $C a$ 'n Reiners (Orfila, Riera, Cau y Arribas, en prensa), en la zona donde estuvo el foro. El suministro de agua a la ciudad se efectuaba mediante un acueducto que canaliza el agua desde varios kilómetros de distancia y pozos en su interior (Arribas, Tarradell y Woods, 1973: 24-25). Las necrópolis conocidas son (Arribas, 1978: 148): Ca'n Fanals, descu-

${ }^{4}$ En Pollentia destacamos las efectuadas en los años veinte y treinta por G. Llabrés y R. Isasi (Llabrés, Isasi, 1943; Arribas, Tarradell y Woods, 1973; Merino, 1994) y las promovidas por la Bryant Foundation efectuadas ininterrumpidamente desde los años cincuenta hasta la actualidad y de las que han sido directores A. Arribas, N. Doenges, M. Orfila, M. Roca, M. Tarradell y D. Woods. Cabe señalar aquí los trabajos que M.M. Estarellas y J. Merino han realizado, unas catas de comprobación sobre estos terrenos durante el invierno de 1995/6. Queremos agradecerles aquí el habernos hecho llegar el documento «Informe sobre les intervencions arqueològiques realitzades a prop de la ciutat romana de Pollentia (Alcúdia)», Palma, 1996. bierta en 1930; Sa Solana, excavada en 1950; en el teatro romano aparecieron tumbas al excavarse en 1952; en 1954 se excavó la necrópolis de $\mathrm{Ca}$ 'n $\mathrm{Co}$ rró, conocida también como Ca'n Banya o del Matadero. En 1955 se descubrieron tumbas en $\mathrm{Ca}$ 'n Copido, mientras que en 1956-7 fueron las de la finca de Ca'n Troca (Arribas, 1978: 148). Otra gran necrópolis la componen las más de 200 tumbas tardías documentadas en los niveles superiores de la zona del Foro (Arribas y Tarradell, 1987).

El tamaño de esta ciudad se había calculado en torno a 10 ó 12 ha al utilizar como referencia las necrópolis y el lienzo de muralla de la zona de $S a$ Portella (Tarradell, 1978: 320). En la actualidad la ciudad parece medir 12 ó 14 hectáreas, dados los resultados de los sondeos ya citados efectuados al oeste del Camino del Cementerio, documentando allí restos constructivos hasta unos $120 \mathrm{~m}$ al oeste de esta línea de muralla que había sido considerada como límite de la ciudad.

\section{LOS INICIOS DE LA CIUDAD}

El año 123 a.C. ha sido considerado siempre el inicio de la ciudad de Pollentia. Esta afirmación puede cuestionarse si tomamos como argumento el que tuvo que pasar un tiempo entre la conquista militar de la isla del 123 a.C. y la fundación y pues- 
ta en marcha de los organismos de una ciudad, hecho que debió producirse con la implantación en el foro de las instituciones que la regían. En Pollentia las primeras edificaciones documentadas de este espacio público quedan datadas en la primera mitad del siglo I a.C., concretamente entre los años 70 y 40 a.C., no habiéndose identificado ninguna edificación correspondiente al período prerromano (Orfila y Arribas, 1997: 64; Orfila, en prensa; Orfila, Arribas y Doenges, 1999).

Materiales romanos del último cuarto del siglo II a.C. se han documentado en los sondeos de la Calle Porticada de Sa Portella (Arribas, Tarradell y Woods, 1975 y 1978; Fernández-Miranda, 1983: 29). Dichos materiales se hallaron directamente relacionados con estructuras de la cultura talayótica, con un inicio del hábitat en el siglo Iv a.C. (Sanmartí et alii, 1996: 67) ${ }^{5}$.

Estos datos permiten retomar la interpretación que publicara Mattingly en 1983 sobre la fundación y categoría jurídica de Pollentia. Este autor, basándose en la circulación monetaria y en las fuentes literarias, piensa que, si bien se ha considerado el año 123 a.C. como fecha de arranque de este espacio urbano, la documentación de numerario anterior al primer cuarto del siglo I a.C. es demasiado escasa como para poder pertenecer a una urbe de la entidad de Pollentia, considerada además, según la interpretación que se haga de las fuentes escritas, con rango de colonia desde el momento de conquista, el 123 a.C. ${ }^{6}$. Para Mattingly (1983: 245-6) tanto Pollentia como Palma debieron ser reforzadas después de la guerra entre Sertorio y el senado romano. Vencido Sertorio por Pompeyo en el año 72 a.C., se llevó a cabo una reorganización administrativa de la península ibérica que debió afectar también a las Baleares. De hecho, los nombres de Palma y Pollentia con ese significado de Victoria y Poder tendrían más sentido, como Mattingly indica, en estas fechas del primer cuarto del siglo I a.C. y no en el año 123 a.C. 7 .

${ }^{5}$ La identificación de estos restos prerromanos queda valorada por Bendala al incluir Palma y Pollentia entre las primeras fundaciones romanas en Hispania, que, como todas ellas, casi ninguna es ex novo: Italica, Tarraco, Gracchurris, Carteia, Corduba y Valentia, además de las dos de Baleares (Bendala, 1990:29).

${ }^{6}$ El estudio se realizó sobre los hallazgos de las excavaciones entre los años 1957 y 1969 en el barrio residencial de Sa Portella.

7 No vamos a entrar en el tema de la categoría administrativa de Pollentia desde el 123 aC., al que ya hemos hecho referencia en otras notas y sobre el que se ha escrito ya mucho. No obstante, es significativa la cita de Plinio al referirse a este enclave y a Palma como oppida, no pudiéndose descartar la existencia de un posible castrum para el establecimiento del contingente de tropas romano llegado a la isla en el año ya indicado, pero del que no se tiene actualmente indicio alguno.

\section{EL FORO DE POLLENTIA: DESARROLLO CRONO-ESTRATIGRÁFICO ${ }^{8}$}

En 1980 se iniciaron las excavaciones sistemáticas en una zona de Pollentia conocida bajo el topónimo de Ca'n Reines, una de las divisiones del anterior Camp d'en França. La elección de ese lugar no fue casual; una serie de indicios (Arribas y Tarradell, 1987) permitían considerar que el foro de la ciudad debía localizarse en aquel paraje. Desde el siglo XVII se han recuperado en estos terrenos, o zonas circundantes, numerosos restos, muchos de ellos epigráficos de cariz honorífico. Arribas y Tarradell mencionan las CIL II, 3696 y 3697, con la indicacion L D D D, halladas en el Camp d'en França, o la CIL II, 5900, en la que aparece la mencion (RE) SP POLL(entina) (Arribas y Tarradell, 1987: 123). Por otra parte hay que destacar los objetos recuperados por el equipo de G. y J. LLabrés y R. Isasi (Llabrés e Isasi, 1934; Arribas, Tarradell y Woods1973; Merino, 1994) ${ }^{9}$. Por último, la posi-

${ }^{8}$ La excavación del foro se ha encontrado con problemas añadidos a los habituales: toda una serie de acciones deposicionales naturales y antrópicas que han afectado el yacimiento. En primer lugar la reutilización, ya sea en época romana como en la Antigüedad tardía, de elementos constructivos o decorativos en las edificaciones del momento. En segundo, destaca la extracción de sillares, documentada desde época medieval islámica y que continuó durante el Medioevo cristiano. Recordemos que la actual población de la Alcudia, al lado de Pollentia, fue fundada en el s. xiII y ha necesitado un gran volumen de piedra para edificaciones y recintos amurallados, ya fuera el del s. XIv o las defensas de la época de los Austrias. Hay que añadir la siembra masiva de almendros en toda la isla a partir del s. xIx, llevada a cabo también en Pollentia. Además, Arribas y Tarradell indican cómo afectó al yacimiento el método utilizado en las excavaciones iniciadas en 1923 por Llabrés e Isasi, que, al trabajar en propiedades privadas, realizaban trincheras entre los almendros, que eran rellenadas una vez concluidas las excavaciones «no sin antes haber arrancado los respectivos propietarios los sillares de los muros para reaprovecharlos» (Arribas y Tarradell, 1987: 123-4). En los años setenta se llevó a cabo un rebaje del terreno en los cercados comprados por el Estado y que identificamos como Camp d'en França y Ca'n Reines.

9 Excavaron en Camp d'en França, Santa Aina de Ca'n Costa, Ca'n Costa, etc. Tuvieron espectaculares hallazgos arquitectónicos decorativos, como se aprecia en las fotografías que nos han llegado de las zonas de Santa Aina o Ca'n $P i ́$. Destacamos los procedentes de la finca de Ca'n Mostel recuperados durante la campaña de 1935: un togado datado en la segunda mitad del siglo I a.C., una estatua acéfala de una matrona como la anterior, datada ésta en el siglo i d.C., o un torso thoracato. En la zona de Camp d'en França, finca de Ca'n Viver, fue hallada en 1927, también durante los trabajos de Llabrés e Isasi, una estatua, posiblemente de una Puditia. De estos hallazgos no se conoce el lugar exacto. En las ocasiones anteriores conocemos la finca pero no tenemos un plano que nos indique con precisión el lugar. No obstante, la revisión de una documentación inédita de las campañas de 1923 y 1926 procedente de la Biblioteca G. Llabrés de Palma de Mallorca, así como los datos aportados por P. Ventanyol (Merino, 1999), han permitido conocer hoy mejor el 
ción central de este espacio respecto al plano de la ciudad era un indicio a considerar ${ }^{10}$. Las excavaciones sistemáticas emprendidas en los años ochenta han confirmado esta ubicación del foro del cual se ha recuperado por ahora una extensión de unos $2.500 \mathrm{~m}^{2}$ (fig. 2). Se han identificado tres templos: el Capitolio al norte y otros dos al este; una plaza pública de la que por el momento no se puede asegurar que estuviese enlosada ${ }^{11}$, con diversos edículos y basamentos honoríficos, fragmentos de inscripciones, y dos grupos de tabernas, uno formando una insula porticada en sus lados este y oeste que limita el foro por el Oeste, y otro grupo de tabernas al norte del Capitolio. Con posterioridad a ese uso, la zona se ocupó por un recinto fortificado y después, posiblemente en época medieval, por una gran necrópolis (Arribas y Tarradell, 1987; Equip d'Excavacions de Pollentia 1994 a y b; Orfila y Arribas, 1997; Orfila, Riera, Cau, y Arribas, en prensa).

La secuencia cronológica documentada en el foro es la siguiente ${ }^{12}$ :

- Inicio en el siglo I a.C. al que pertenecen la preparación o nivelación del terreno virgen en casi la totalidad del espacio ocupado por el foro, una tierra blanquecina (blanquet) que tiene un porcentaje elevado de cal, a unas cotas en relación al punto cero cercano al $2,85 \mathrm{~m}$. Sobre esta nivelación se asentaron los pavimentos de uso consistentes en unas piedras de arenisca (marés) identificados en las habitaciones A, B y Z con un grosor que oscila en torno a unos $20 \mathrm{~cm}$ y que está a una cota en relación al punto cero de entre 2,60 y $2,50 \mathrm{~m}$.

- Una reforma del siglo i d.C. de la que se tienen pocos datos, pero suficientemente explícitos. En la Hab. B se documenta en la cota 2,26 m, un pavimento también de marés que eleva el pavimento unos $25 \mathrm{~cm}$ sobre el de época republicana.

- Unos fuertes cambios en toda la ínsula al oeste del foro que podemos situar a fines del siglo

lugar de procedencia de piezas significativas. En la campaña de 1927 se hallaron una representación de un Esculapio y un Telesforo, ambos de bronce, en el Camp d'en França, de donde también procede el estandarte de un Collegium iuvenum.

${ }^{10}$ Hay que añadir que estas tierras habían sido expropiadas por el Estado Español, operación concluida en 1973 (Arribas y Tarradell, 1987:123).

"En un sondeo efectuado durante la campaña de verano de 1996 en la zona del Pórtico al oeste del Foro, concretamente entre los cuadros E-15 y E-16, se identificaron unas losas que podrían pertenecer al enlosado de esta plaza pública.

${ }_{12}$ En estos momentos se está preparando un proyecto para llevar a cabo una interpretación más exhaustiva del foro de Pollentia. Dicho proyecto va a estar avalado por el Consell Insular de Mallorca
II d.C. y que afectan tanto al módulo de las habitaciones como a la técnica constructiva, elevando de nuevo el piso y llegando ahora los cimientos a la cota de $2 \mathrm{~m}$ y sobre $1,80 \mathrm{~m}$ el pavimento de uso. El suelo se ha elevado de nuevo, esta vez en torno a los $35 \mathrm{~cm}$ sobre el anterior y a un metro del republicano. Esta reforma se ha documentado secuencialmente en las habitaciones A, B, F y Z.

- La destrucción de estas estructuras, consecuencia de un fuerte incendio producido a finales del siglo III d.C., sobreeleva de nuevo el terreno, esta vez debido a la acumulación de los escombros del incendio.

- Sobre el nivel de escombros se identifican en algunos puntos del foro unos restos de pavimentos de opus signinum que se pueden apreciar en la Hab. Q y al exterior de la Hab. Y, a una cota en torno a $1,20 \mathrm{~m}$.

- La edificación de un recinto fortificado al norte de la ínsula de tabernae, al oeste del foro y del propio Capitolio, fechable a mediados del siglo v d.C.

- Necrópolis altomedieval.

- Período medieval islámico.

\section{EL FORO DE POLLENTIA EN ÉPOCA REPUBLICANA}

La urbanización de esta zona pública de la ciudad, el foro, iniciada durante el siglo i a.C., estuvo precedida, como se ha mencionado, por un trabajo de ingeniería que consistió en la nivelación de la tierra blanquecina de la zona, ya fuera recortándola como acarreándola y acumulando tierra que, por cierto, tiene un elevado porcentaje de $\mathrm{cal}^{13}$. Esta nivelación ha sido identificada hasta la actualidad en las habitaciones B, A y Z, en el pórtico de la calle oeste, el Capitolio y la zona del recinto fortificado, con unas variaciones en profundidad en relación al punto cero que va desde 2,92 a $3,03 \mathrm{~m}$ en la zona del recinto fortificado, $2,91 \mathrm{~m}$ en la Hab. B, y 3,10 $\mathrm{m}$ en el pórtico de la calle oeste, concretamente delante de la Hab. Z.

${ }_{13}$ La recuperación de materiales cerámicos procedentes de las primeras capas de esta tierra blanquecina, conocida en Alcudia como blanquet, nos lleva a plantear este tipo de nivelación: recorte y acumulación. Análisis efectuados al blanquet procedente de diferentes lugares del foro indican que está formado por una mezcla de cal y arena: Hab. B, unidad estratigráfica $5230,40 \%$ de cal y $60 \%$ de arena, y en el recinto fortificado la unidad estratigráfica 5297 con un porcentaje de $49 \%$ de cal y $51 \%$ de arena. Los análisis han sido efectuados por al Dra. J. Capel en el Centro Experimental del Zaidín (C.S.I.C.), Granada 
Por el momento se ha comprobado el uso en el siglo I a.C. de los siguientes elementos del foro (fig. 2) ${ }^{14}$ : una serie de tabernas de la ínsula de tabernas al oeste del foro, los pórticos al este y oeste de la misma, el Capitolio y posiblemente algún edículo ${ }^{15}$.

De la insula de tabernas al oeste del foro podemos afirmar que estaban en uso en estos primeros momentos las Habitaciones (tabernae) A, B y Z (Orfila y Arribas, 1997). Hay que añadir a estos datos las referencias a los sondeos efectuados en las Hab. M y N (Sanmartí et alii, 1996), además de la excavación de un pozo (D-18) en la Hab. C (Equip d'Excavacions de Pollentia, 1993), con la misma cronología (Orfila, en prensa). En todos los casos se documenta un piso datado en torno al primer cuarto del siglo I a.C., caracterizado por haberse fabricado a base de pequeñas piedras de arenisca (marés) que se laminan. La estructura urbana de este momento de época republicana queda definida por unos espacios de forma rectangular, como los que apreciamos en la Hab. Z, o en la A. En esta última las medidas son de Norte a Sur 3,60 m y de Este a Oeste 4,30 m.

En este primer nivel los materiales muebles se caracterizan por ser prioritariamente importados (vajilla de barniz negro, paredes finas, cocina itálica, piezas ebusitanas, etc.), pero en todos estos conjuntos de materiales aparecen piezas hechas a mano de tradición prerromana, talayótica. La interpretación de este dato es muy sencilla: la fundación de la ciudad se hace no sólo con foráneos, sino que participa en ella la población indígena isleña ${ }^{16}$. Estaban aún presentes entre estas gentes piezas de mesa utilizadas desde hacía varias centurias; quienes las fabricaron en el siglo i a.C. eran los descendientes directos de

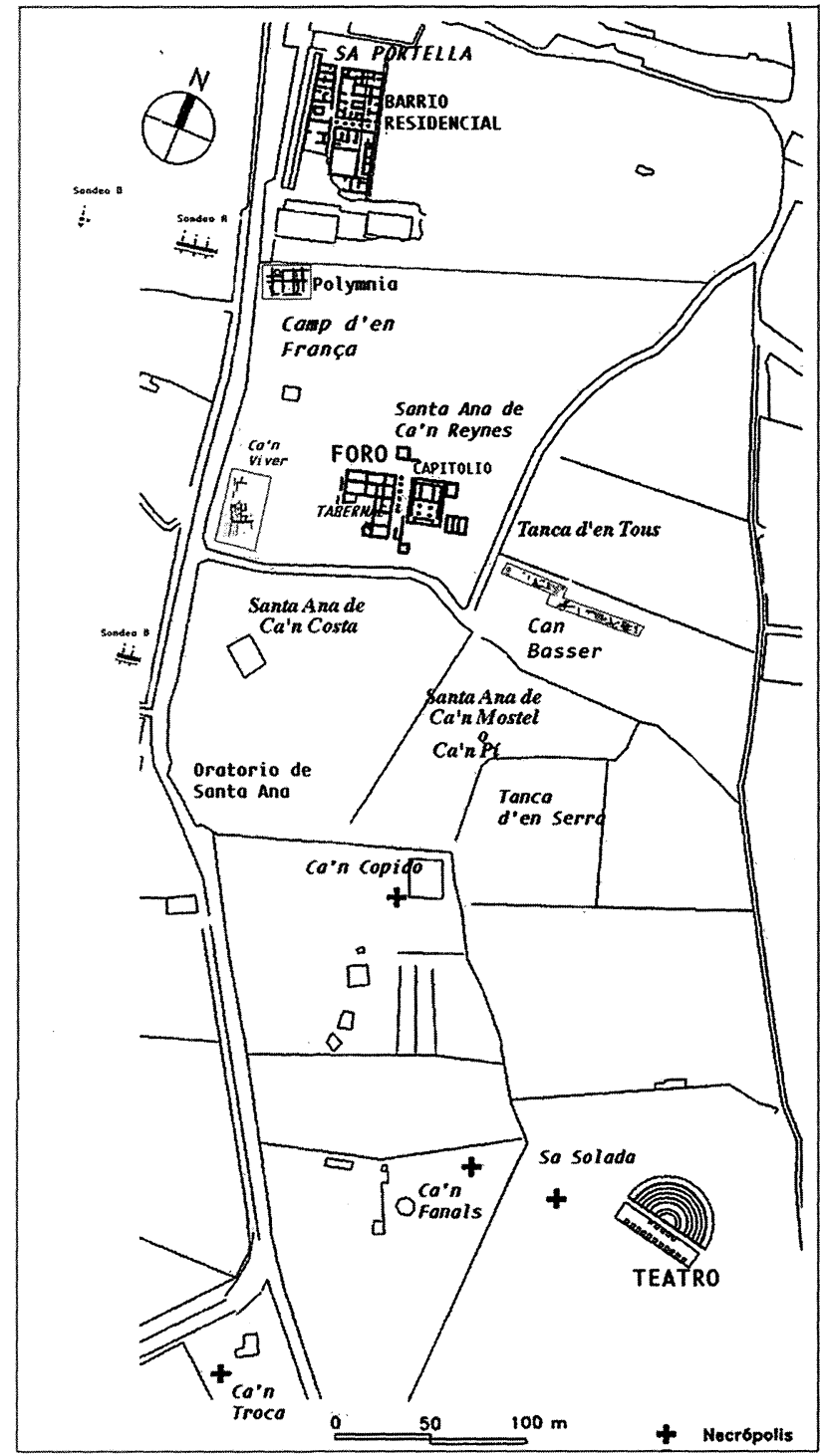

Fig. 2.-Plano general de Pollentia con la ubicación de las principales estructuras excavadas desde los años cincuenta.

${ }^{14}$ Fecha posible de inicio del uso del foro: «La primera organizació arquitectònica de la zona sembla datar de la primera meitat ja lleugerament avançada del segle I a.C.» (Equip d'Excavacions de Pollentia, 1994b:142).

15 Además de los datos descritos infra, proceden del foro desde su excavación en 1980 cerámicas o monedas del siglo I a.C. De éstas Mattingly constata la presencia de escasas monedas republicanas, como dos «ejemplares romano-republicanos del cuadro I-11 (estudio preliminar, aún sin publicar). Las piezas hispánicas son asimismo rarísimas -por ejemplo una de $A c c i$, en la cámara M-» (Arribas y Tarradell, 1987:133). Excavaciones posteriores han registrado otros numarios, a ellos nos vamos a referir en sus apartados correspondientes.

${ }^{16}$ Estrabón da una referencia concreta $(3,5,1)$ : «de las Gymnesias, la mayor tiene dos ciudades, Palma y Pollentia, de las cuales, una, Pollentia, se halla al este y Palma, al oes-

quienes las habían utilizado durante el período talayótico ${ }^{17}$.

te ... Metello el Baleárico pasó a las islas y fundó allí las dos ciudades citadas... Llevó como colonos a tres mil romanos de Iberia». Ilustrativo es el caso de Orange, Francia, donde, a través de las anotaciones de los parcelarios allí realizados sobre unas placas de mármol, concretamente sobre la Tabulae $\mathrm{B}$ de época cesarea-triunviral, cita que el origen de los que ocuparon estos terrenos divididos en centurias fueron tanto colonos alienos, como los propios lugareños, los Tricastrinis, en un porcentaje del $36 \%$ (Piganiol, 1962).

17 Existen materiales de tradición talayótica en niveles romanos incluso en el siglo I d.C., como en la villa romana de Sa Mesquida en Calvià, donde se ha localizado el vertedero y horno de un alfar donde se fabricaba cerámica a tor- 
Podemos suponer que el pórtico oeste del foro funcionaba también a inicios del siglo I a.C. Este pórtico está justo a $5 \mathrm{~m}$ de distancia de la pared del Capitolio. De él se han conservado seis bases de columnas con intercolumnios de unos $3 \mathrm{~m}$, la base de las columnas mide $0,90 \mathrm{~m}$ mientras que los fustes tienen $0,60 \mathrm{~m}$ de diámetro. La anchura del pórtico es de $2,70 \mathrm{~m}$, y su longitud conocida es de unos $20 \mathrm{~m}$. Se puede afirmar que el pórtico que está en la fachada oeste de la insula, en la calle oeste funcionaba en este primer cuarto del siglo I a.C. ${ }^{18}$. Está formado por cuatro pilastras en vez de columnas, equidistantes unos $3 \mathrm{~m}$. Por debajo del nivel de suelo de la calle republicana ha aparecido una cloaca que está abierta en la nivelación ya mencionada de tierra blanquecina.

ACTIVIDAD ECONÓMICA: LA ÍNSULA DE TABERNAS AL OESTE DEL FORO

La ínsula de tabernas que existe al oeste queda delimitada al Este por el pórtico que da a la plaza del foro que acabamos de describir, y que es conocido como el pórtico oeste del foro. El límite oeste de esta ínsula se ha documentado por un pórtico.

Esta ínsula ha sido excavada en extensión, estando centrada la investigación en las estructuras que estuvieron en uso durante el siglo III d.C. (fig. 2). Las intervenciones en profundidad en diversos ámbitos de la ínsula han permitido documentar las cronologías más antiguas del foro hasta ahora.

\section{La habitación $Z$ y su pórtico}

La Hab. Z ha sido excavada casi en su totalidad (fig. 3). Su secuencia estratigráfica permite identificar claramente dos períodos, uno perteneciente al siglo III d.C., registrado como complejo estructural (CE) 8, y un segundo de época republicana, CE 9, estando mal documentada la época alto imperial ${ }^{19}$.

no, realizándose todavía en el siglo I d.C. piezas a torno que parecen imitar un tipo de vasijas postalayóticas, las copas crestadas (Cau, Cardell y Orfila, en prensa). En otros yacimientos se ha identificado la imitación a mano de piezas claramente romanas como las paredes finas, así las procedentes de los ajuares de la necrópolis de Sa Carrotja (Orfila, 1988) o de la del ager pollentino (Arribas y Llabrés, 1983).

18 Este pórtico que incluimos en la descripción del foro está realmente al exterior del mismo.

${ }^{19}$ La campaña de excavaciones de 1998 ha puesto al descubierto el límite sur de este ámbito, identificándose su evolución secuencial en tres fases constructivas muy claras: zócalo (UE5358) y primeras hileras de época republicana (UE5359), sobre ellas la fase alto imperial (UE5361), rematadas por las últimas hileras correspondientes a la fase constructiva de fines del siglo II o inicios del III d.C. (UE5363).
Conocemos del CE 9 (fig. 4) las estructuras murarias 38 (UE5065), 47 (UE5135), 84 (UE5358 cimentación, UE5363 trinchera de fundación, UE5359 tramo de pared republicana) que lo delimitan respectivamente por los lados norte, oeste y sur (fig. 5). No se puede precisar aún su límite este, al meterse el nivel de uso republicano por debajo de la pared este, correspondiente al siglo III d.C. Asociada a este muro está un suelo, Estructura 54 (UE5121 y 5091), compuesto por pequeñas piedras de arenisca (marés) bastante deshechas. Sobre el nivel del CE 9 aparece la UE5039, donde se ha recuperado gran cantidad de materiales, cuyo estudio proporciona una datación que va desde los años 70 hasta los años 50 ó 40 a.C., esta última fecha se documenta por la presencia de tres fragmentos de una misma pieza de terra sigillata itálica precoz ( $\mathrm{n}^{\circ}$ inv. P96/ Z153) ${ }^{20}$. Por debajo del suelo aparecen muy pocos elementos arqueológicos, sólo algunos fragmentos rodados de cerámica a mano talayótica, y ninguna estructura de época anterior.

El lado oeste de la Hab. Z corresponde a la fachada de acceso que da a la Calle Oeste, porticada. En el pórtico se ha localizado una cloaca que, en principio, corresponde a la época republicana (fig. 4). Sus losas están asentadas en la nivelación del blanquet, habiéndose recuperado fragmentos de vajilla de cerámica de barniz negro de inicios del siglo I a.C. Un canal registrado en el interior de la Hab. Z (EU5090) conecta directamente con la cloaca.

La funcionalidad de habitación $\mathrm{Z}$ en época republicana, CE9, tiene que ver, posiblemente, con actividades relacionadas con transacciones de vino, si tenemos presente las seis bases de ánforas itálicas Dressel 1B hincadas en el suelo de la habitación. Se han recuperado también fragmentos de ánforas ebusitanas, así como gran cantidad de piezas de vajilla de barniz negro (formas A, Lamb. 8, 27, 31 y 7-5, y formas B, Lamb. 1, 2, 3, 6), cerámicas hechas a mano, paredes finas (formas Mayet I-Marabini I, Mayet II-Marabini IV y Marabini III), algún fragmento de cerámica megárica o cuencos helenísticos, algunos fragmentos de púnico-ebusitanas, cerámica ibérica pintada y gris, y la pieza de terra sigillata itálica, junto con una gran cantidad de fauna, cerámica de cocina itálica, cerámica común y piezas para hornear, como los fragmentos de rojo pompeyano. Todas estas piezas documentan, además, una actividad cotidiana relacionada con la alimentación y cocción de los alimentos. Cabe señalar la repetición de un mismo grafito $D V I$, sobre cuatro piezas procedentes de esta habitación. Se han registrado

\footnotetext{
${ }^{20}$ En estudio.
} 


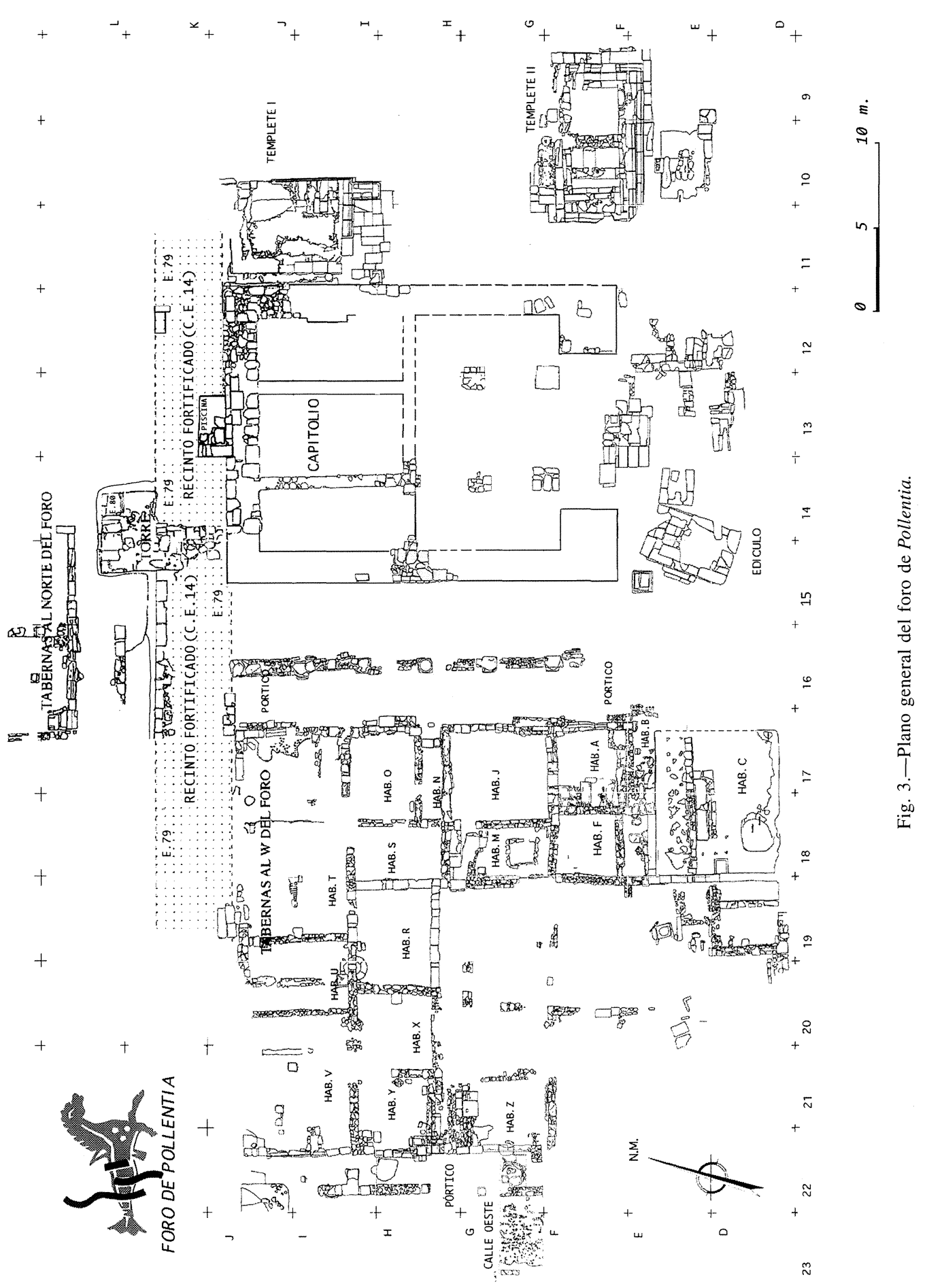




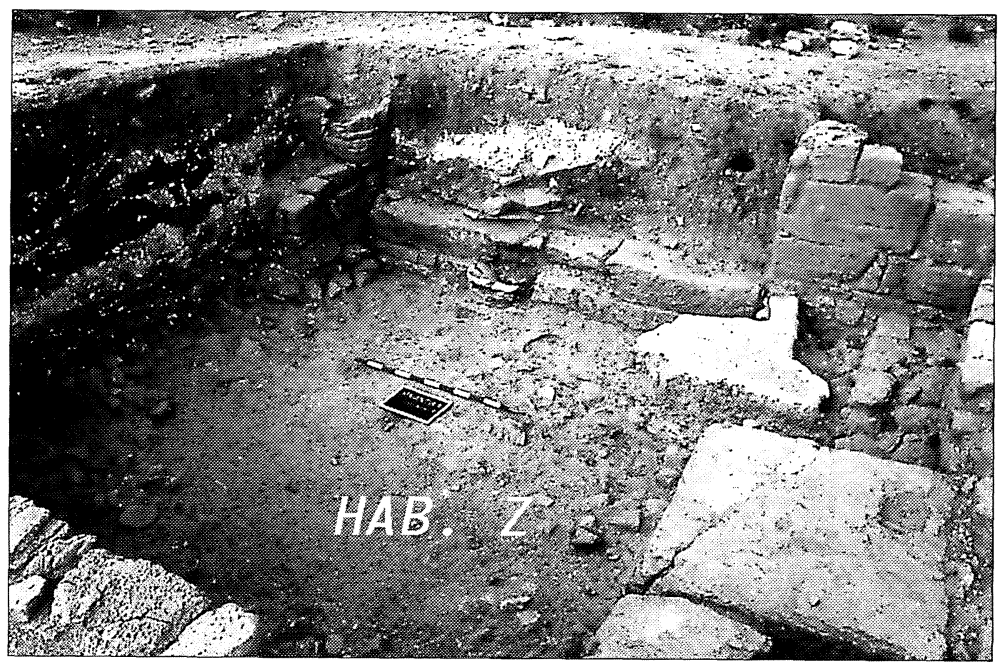

Fig. 4.- Insula de tabernas al oeste del foro. Fotografía de la Hab. $\mathrm{Z}$ en la que se aprecia del nivel de uso de época republicana.

pocas monedas procedentes de los niveles republicanos; destacamos una de ellas, con cabeza de Minerva en su anverso y en el reverso la nave y la leyenda «Roma» en el espacio del exergo.

\section{La habitación A}

En la Hab. A se ha documentado un nivel del siglo III d.C., una fase perteneciente a las primeras centurias de esta era, y los niveles inferiores, CE 2, que corresponden al período republicano (fig. 6). De este último se han identificado hasta la actualidad las siguientes estructuras y unidades estratigráficas: muro norte (E2=UE5002), muro sur $(E 31=U E 5126)$ y muro oeste $(E 13=U E 5014)$. El lado este hasta el momento está sin identificar puesto que su límite nos viene, de momento, marcado por la puerta de acceso que funcionó durante el siglo III d.C. aunque sí podemos intuir como linde el muro que se visualiza en la Hab. B (UE5229), que viene de la Hab. A. Estos muros se asocian a una nivelación de pequeñas piedras de arenisca (marés) (UE5084=E.30). Entre los materiales registrados sobre este suelo de la primera mitad del siglo I a.C. cabe destacar la pieza de barniz negro con el grafito mile.

\section{La habitación $B$}

La excavación de la Hab. B ha producido unos datos muy interesantes al documentarse una secuencia estratigráfica con tres claros períodos: siglo I
a.C., alto imperio y siglo III d.C. Referente a la época republicana, ha de constatarse la clara presencia de una fase constructiva. Sobre ella otra que podemos considerar Alto Imperial que, como se verá más adelante, no se había constatado fielmente en la serie de tabernas de esta ínsula al oeste del foro hasta ahora.

La fase constructiva republicana (fig. 6) queda determinada por dos espacios habitables, el sector oriental denominado Complejo Estructural 12, y el sector occidental o Complejo Estructural 13, divididos por los cimientos de un muro en sentido NorteSur, UE5205, justo en la mitad de este espacio de la Hab. B y del que se tiene un tramo visible de 1,40 $\mathrm{m}$ de longitud. El CE 12 queda delimitado por el ya mencionado muro en el lado oeste, por el muro, UE5126, al norte, al sur los cimientos de otro muro en mal estado de conservación, UE5098, y al este el muro, UE5259; conectada a estos muros aparece una nivelación de arenisca a base pequeñas piezas que se han ido disgregando con el paso del tiempo hasta presentar en la actualidad un aspecto arenoso. El CE 13 queda delimitado por los siguientes muros: este, UE5205, norte, UE5095 y sur, UE5100, no pudiéndose identificar el límite oeste ya que tiene el muro del siglo III d.C. sobre él. Se había perdido por excavaciones anteriores ${ }^{21}$ la nivelación de arenisca que se aprecia en la sección sur, pero sí se ha podido intervenir en la preparación del mismo, blanquet (UE5195), compuesto por vajilla de barniz negro A (Lamb.5/7 y Lamb.31) y B-oide (Lamb.1 y

${ }^{21}$ Nos referimos a la intervención ya citada de las zanjas abiertas por Llabrés e Isasi en los años veinte. 


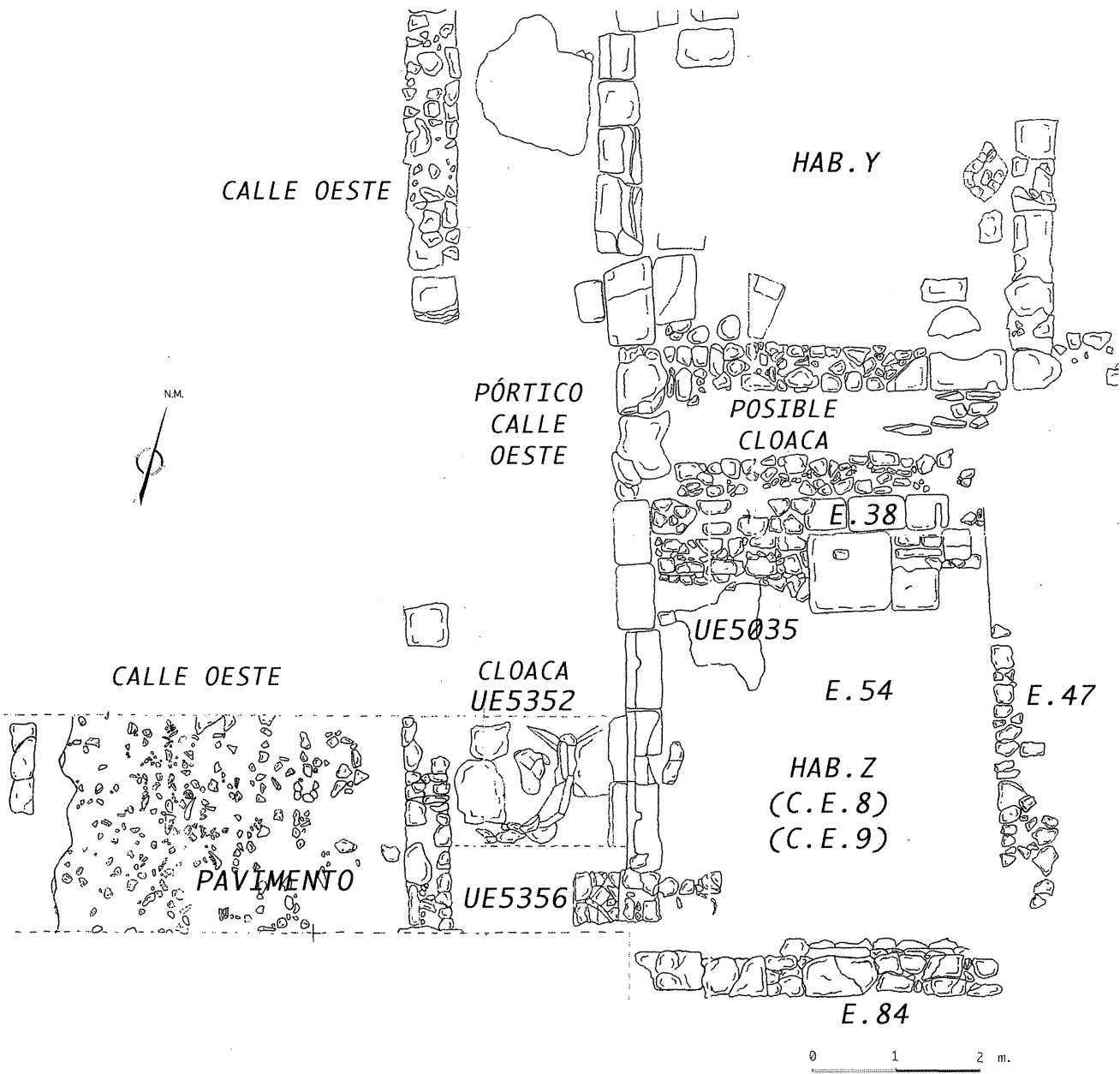

Fig. 5.-Calle oeste con su pórtico frente a las habitaciones Y y Z. Insula de tabernas al oeste del foro.

Lamb.5/7) que remontarían a unas fechas de producción iniciales entre el 90/80 y que pueden llegar a identificarse hasta mediados del s. I a.C.

\section{La habitación C y el pozo D-18}

Durante el desarrollo de la excavación de la habitación B (fig. 6) se identificó el ya mencionado muro, UE5205, de unos 0,5 m de altura, que la cruza en sentido norte/sur, con secuencia por debajo del pavimento de opus signinum (UE5083) de la Hab. C. Este muro marca la división entre dos ámbitos de esta Hab. $\mathrm{C}$ en época republicana, uno en el lado oriental, del que conocemos, además de la mencionada pared que marca su límite este, el muro UE5100 como límite norte, y la unidad estratigráfica 5130 como límite oeste. La otra habitación republicana por debajo de la Hab. C, ésta en el lado occidental, queda delimitada por la UE5205 como límite oeste, la UE5098 el límite norte y la UE5259 el límite este.

Por debajo del pavimento de opus signinum del siglo III d.C. se localizó un pozo, el D-18, que estaría dentro de la habitación occidental ya descrita (fig. 2). $\mathrm{Su}$ relleno está compuesto por materiales cuyas formas repiten las ya mencionadas e identificadas en la UE5195 de la Hab. B. Tenemos que añadir además la forma Lamb. $27 \mathrm{~A}$, que puede tener un inicio y utilización en el último cuarto del siglo II a.C., o la forma Pasquianucci 127/Morel 3121, en B-oide, datable en las fechas más frecuentes en los niveles del 90 al 70, e igualmente presente entre el 70 y el 40 a.C. (Equip d'Excavacions de Pollentia, 1993).

Los sondeos en las habitaciones $M$ y N

Los niveles republicanos de los sondeos realizados en las habitaciones $\mathrm{M}$ y $\mathrm{N}$ (fig. 2) proporciona- 


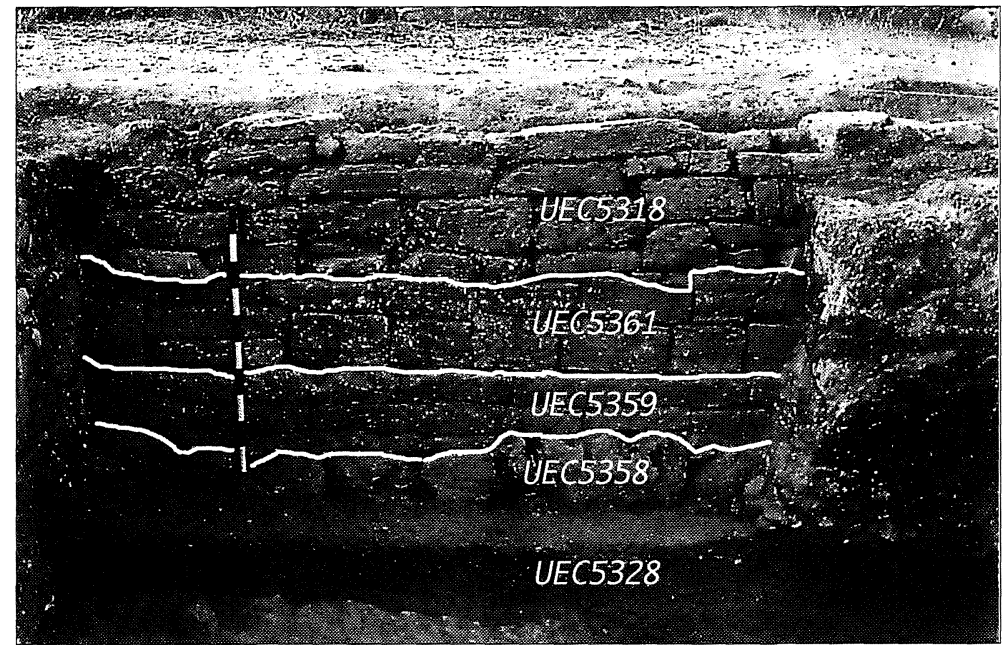

Fig. 6.-Muro sur de la Habitación $\mathrm{Z}$ en el que se aprecian sus diversas fases constructivas: tadorepublicana, alto imperial y siglo III d.C.

ron los mismos tipos y formas de materiales cerámicos recuperados en los otros niveles identificados de esta época en el foro: en piezas de vajilla de barniz negro recuperadas en los niveles inferiores de la Hab. M., las formas son, en producción A, Lamb.5, Lamb.5/7=Morel2252-55, Morel2283-84, Lamb. 8B=Morel2855, Morel2943a1, Morel113, Morel2983, Lamb.31, Lamb.31=Morel2952-54; en producción B o «B-oide», Lamb.5/7=Morel2280, Lamb.5/7=Morel2250, Lamb.5/7, Lamb.4/Morel1410, Lamb.1/Morel2320, Lamb.1/Morel 2300, Lamb.2/Morel 1220; y en producción B, Lamb.3/ Morel7540, Gris, Lamb.10/Morel3450, Lamb.5 ó 7 /Morel2300 (Sanmantí et alii, 1996). Estas piezas abarcan un margen cronológico que va desde el 90 al 70 a.C., llegando hasta el 40 a.C.

En la Hab. $\mathrm{N}$ se recuperaron ejemplares de las mismas formas 22 .

\section{LAS ESTRUCTURAS RELIGIOSAS DEL FORO EN ÉPOCA REPUBLICANA}

\section{El Capitolio}

El templo identificado como Capitolio está ubicado al norte del foro (fig. 2). Trazado en sentido Norte-Sur, su fachada de acceso está orientada al Sur. Tiene las paredes muy expoliadas, pero aún así podemos decir que fue construido según el módulo

${ }^{22}$ En los veranos de 1993 y 1994 N. Doenges, en colaboración con $\mathrm{T}$. Partment, realizaron diversos sondeos de 50 por $50 \mathrm{~cm}$ en diferentes zonas del foro, documentándose en todos ellos un inicio de uso de este espacio en la primera mitad del siglo i a.C. base de las medidas romanas, el pie romano: 29,6 $\mathrm{cm}$. Su podio mide $23 \mathrm{~m}$ de largo (sentido $\mathrm{N}-\mathrm{S}$ ) por $18 \mathrm{~m}$ de ancho (sentido E-O). La pared norte es la que está en mejores condiciones. Tiene 1,80 m de anchura por 18 de largo, la altura máxima conservada es de 1,40 m, de la cual hay que restarle unos $0,50 \mathrm{~m}$ correspondientes a los cimientos. Está formada por dos paramentos compuestos por bloques de arenisca con unas medidas que oscilan entre 1,20 $\mathrm{m}$ por 0,30 , a 0,48 por $0,20 \mathrm{~m}$. Los muros laterales se ensanchan por sus lados sur para enmarcar la escalinata de acceso que ocupaba la parte delantera del templo, con una anchura de 9,30 m. En el interior se ha documentado una división tripartita en cellas de 5 por $9 \mathrm{~m}$ la central y 4 por $9 \mathrm{~m}$ las laterales, precedidas por un vestíbulo de $7 \mathrm{~m}$ de profundidad sostenido por dos hileras de dos columnas cada una (Equip d'Excavacions de Pollentia 1994a: 217).

La delimitación de los cimientos está perfectamente de acuerdo con los preceptos vitrubianos, pero no así la restitución de la planta. Ello implica que si bien este capitolio de Pollentia es, grosso modo, del tipo canónico de los templos toscanos, se trata de una aproximación en base a sus cimientos, pudiendo restituirse de diferentes maneras su planimetría, desde la versión mixta in antis con una hilada de columnas frontal como en el Capitolio de Cosa, a un pronaos tetrástilo de dos hiladas de columnas documentado en Orvieto (Subías, 1994: 220-224). Podría ser un modelo arcaizante del que se disponen paralelos arqueológicos fechados en el siglo II a.C. Como indica Subías, estaríamos «frente a un templo con una planta ligeramente menos cuadrada que la estipulada por los templos toscanos, colocada sobre un podio alargado, que sugiere una 
síntesis de las tradiciones etrusco-itálicas y helenística. Esta hibridación de corrientes estilísticas es evidente, además de en la forma, en el método de proyección que descansa sobre un sistema modular» (Subías, 1994: 224) ${ }^{23}$.

\section{Edículo 2}

Existe una estructura ubicada en el lado oeste de la plaza del foro (fig. 2), identificada como Edículo 2 (Arribas y Tarradell, 1987: 125), o Estructura III (Equip de Pollentia, 1994a: 217-129), de $5 \mathrm{~m}$ por 3 $\mathrm{m}$, que llama la atención por ser la única que se halla orientada a los cuatro puntos cardinales. Fue publicada como posible base de la estatua ecuestre de bronce de tamaño natural (Arribas y Tarradell, 1987: 125), hallada en las excavaciones de Llabrés e Isasi de $1923^{24}$ (Merino, 1994: 45). Sin embargo no parece lógico que una estatua de tales proporciones se hubiera colocado con una orientación que no se alineaba con el Capitolio. Además, haciendo un cálculo del tamaño real de la estatua resulta que este edículo, según indica Partment, no tiene superficie suficiente para albergarla (Partment, 1995).

Se tuvo también en cuenta la posibilidad de que fuese una tribuna de arengas (Arribas y Tarradell, 1987: 125), pero no parece que hubiera espacio suficiente para un individuo. Para otros este edículo habría podido tener la funcionalidad de un templete o rostra (Equip de Pollentia, 1994b: 142).

Partment, al compararlo con otros monumentos, plantea el que fuese un altar, el altar del Capitolium concretamente. Piensa también que, debido a la propia orientación del edículo, éste se hubiese construido antes del propio Capitolio (Partment, 1995).

23 Junto a todas estas consideraciones recogemos la opinión de Partment que considera que este templo podría haber sido construido en época de Augusto (Partment, 1995).

${ }_{24}$ Arribas y Tarradell indican que el hallazgo de esta estatua debió producirse en 1927, ya que fue ese año cuando se entregó al Museo Arqueológico Nacional de Madrid, dato erróneo después de haberse revisado en estos años la documentación original e inédita de la biblioteca de Llabrés, en la que aparece no sólo la fecha de su hallazgo, 1923 (Merino, 1994: 45), sino que, además, se sabe incluso el lugar exacto de su extracción, en la finca de Can Costa, en lo que parece una casa particular decorada con pavimento musivario, justo en el extremo sur del impluvium, donde aparecieron, como describe el propio excavador, la cabeza, el cuello, tres patas y las crines, todas las piezas esparcidas por la habitación junto a ellas, la hoja de oro de yedra. La presencia de esta hoja se interpretó como la corona del jinete de esta estatua equestre (Merino, 1999). La finca de Can Costa se halla a unos 70 metros en dirección sur de la parte del foro descubierto hasta la actualidad. Si es una casa pública el lugar de hallazgo, pensamos que la ubicación en ese lugar debe considerarse como deposición secundaria, no la original que debió ser el espacio público del foro.
A estas interpretaciones hay que sumar la de un posible mundus posteriormente conocido como $\mathrm{um}$ bilicus urbis, el pozo de unión entre la tierra y el infierno donde los fundadores de las ciudades tiraban tierra como compromiso de permanencia, a modo de ara de Saturno, dado además su orientación cardinal (Gros y Torelli, 1992: 83).

\section{EL FORO DE POLLENTIA EN ÉPOCA ALTO IMPERIAL}

En los dos primeros siglos posteriores al cambio de era continuaron en el Foro de Pollentia las actividades que ya se han documentado en la época republicana: la comercial, la religiosa y la honorífica.

La actividad comercial está principalmente documentada por restos muebles ya, que son escasos los inmuebles identificados hasta la actualidad relacionados con estos menesteres. Se han recuperado piezas de vajilla sigillata, vasos y tazas de paredes finas, fragmentos de ánforas, lucernas ${ }^{25}$, monedas ${ }^{26}$, etc., aunque en la mayoría de las ocasiones descontextualizados. Los oficios religiosos se continuaron realizando en los templos que señalaremos ahora, quedando plasmados los actos honoríficos por un fragmento de escultura en mármol blanco, un togado de tamaño mayor al natural recuperado en el cuadro E-9, junto a la fachada sur del Templete II (Arribas y Tarradell, 1987: 125), así como siete fragmentos de inscripciones oficiales, identificándose una posible dedicación a Druso, otra puede que a Lucio Vero y una tercera a Licinio/Galieno (Arribas y Tarradell, 1987: 131).

\section{ESTRUCTURAS COMERCIALES: TABERNAE}

Son pocos los indicios que se tienen sobre la ocupación de la insula de tabernas al oeste del foro en época alto imperial, aunque sí suficientes para poder afirmar que se llevaron a cabo unas reformas, posiblemente en el siglo i d.C., que afectaron al trazado anterior republicano.

${ }^{25}$ Los materiales recuperados desde los inicios de las excavaciones del foro muestran una gran cantidad de fragmentos y piezas pertenecientes a los primeros siglos del cambio de era. En espera de su publicación nos remitimos al realizado sobre lucernas por Palanques, donde se recogen materiales del foro hasta la campaña de 1988 (Palanques, 1992).

${ }_{26}$ El estudio de Mattingly, aún sin publicar, sobre la circulación monetaria del foro (Arribas y Tarradell, 1987:33), indica la presencia de numarios imperiales, e indica que son poco frecuentes los ejemplares julio-claudios, siendo mucho mayor la presencia de monedas de los Flavios, apareciendo en todas las áreas del foro monedas desde fines del siglo hasta final del siglo II d.C. 
Esta insula (fig. 2) muestra sus correspondientes pórticos: el pórtico al oeste del foro, detectado por sus intercolumnios, y el pórtico de la fachada oeste de la ínsula por sus pilastras. De hecho uno de los niveles más claros alto imperiales está en la calle oeste, justo en el pórtico delante de la Hab. Z (fig. 4), sobre la cloaca descrita en el apartado dedicado a la época republicana. Del siglo I d.C. se ha documentado un nivel de tierra, UE5342, y un nivel de piedras, UE5344, fechados por los materiales que contienen: fragmentos de cerámica de paredes finas con decoración de «arenilla», características del siglo I d.C., como la ${ }^{\circ}$ inv. P98-5343-2-1 y 2, y un fondo de terra sigillata itálica, forma Goudineau 23 ( $\mathrm{n}^{\circ}$ inv. P98-5343-3-1) cuya cronología también nos lleva al siglo I d.C.

En la habitación B (fig. 6) queda constatada una secuencia estratigráfica situada justo en la intersección entre las habitaciones B, A y F, la cual está compuesta por diversos estratos. La unidad estratigráfica 5226 (pavimento de arenisca del siglo I d.C.), que va sobre diversas unidades republicanas. Sobre este pavimento alto imperial se acumulan unos niveles de ocupación con capas de cenizas, signos de incendio $\mathrm{y}$, sobre todos ellos, la pared que delimita las tabernas A y B, UE5011, del siglo III d.C.

En la Hab. A es donde se ha documentado mejor elementos del siglo I d.C. (fig. 6), destacando especialmente un pozo negro ubicado en su lado oeste, cortando el pavimento de piedras de arenisca republicano, e insertado entre las paredes sur y oeste de la estructura republicana. Para la cubrición del mencionado pozo utilizaron dos grandes losas de arenisca, marés. Una de las losas tiene un orificio o sumidero, UE5238, en su interior, UE5183, se recogieron una pieza de cerámica común y algún fragmento de Terra Sigillata Clásica, datados ambos en el siglo I d.C. Sobre el orificio se situó una canal de arenisca, marés, UE5138, que a su vez queda conectada a una conducción realizada de argamasa, UE5171, asentada sobre la pared republicana que divide la Hab. A con la F (UE5014).

La excavación al norte del Capitolio ha identificado dos posibles tabernae, denominadas recintos 01 y 02 (fig. 2). La cronología de estas dos edificaciones se ha situado en torno al siglo II d.C. (Equip de Pollentia 1994a: 220). Dada su ubicación en relación a las tabernae de la ínsula al Oeste del Foro, como se aprecia en la fig. 2, podemos considerar estos dos recintos como componentes de otra insula de tabernas, esta vez al norte del foro, cerrando y dando fachada a la plaza por el norte, al menos, a partir del siglo it d.C.

\section{LOS EDIFICIOS RELIGIOSOS}

El Capitolio (figs. 2 y 8 )

En principio el edificio capitolino de Pollentia continuaría funcionando en época alto imperial, pero no sabemos si dedicado a la tríada. Se documenta una reforma que afecta directamente el exterior de su pared norte. Nos referimos a un depósito o piscina de opus signinum de 1,22 $\mathrm{m}$ de ancho por 2,26 m de largo, ubicado justo en el centro del muro. Este depósito podría interpretarse como un componente del mismo templo asimilándose, salvando distancias puesto que los de los ejemplos comparativos tienen superficies mucho mayores que el de Pollentia, a otros templos en donde aparecen estanques rodeando la edificación, como el de Évora, excavado por Hauschild, con una datación augústea, o el de Diana de Mérida ${ }^{27}$. Estos estanques en otros monumentos se relacionan con el culto al emperador.

La interpretación dada a este depósito no puede pasar de una hipótesis, puesto que está muy deteriorado por la construcción de un recinto fortificado en el siglo $v$ d.C. que lo rellenó con bloques y argamasa para pasar a formar parte del propio muro de esta obra defensiva. Ello implica que en la actualidad no se pueda saber desde dónde llegaba el líquido que debía almacenarse en el depósito, ni por dónde se extraía. Ignoramos también si estaba directamente conectado con alguna función del Capitolio.

\section{Los templetes I y II (fig. 2)}

Parece que los otros dos templos del foro, uno en el lado este, el Templete I, y otro más al sur conocido como Templete II, estuvieron en uso durante la época alto imperial, sin que se sepa de ellos el momento exacto de su edificación.

El Templete I está en el lado este del Capitolio y alineado con él. Tiene 7,20 m sentido norte-sur y $5,70 \mathrm{~m}$ este-oeste, su pared oeste conserva un almohadillado. Se le asocia una crestería de arenisca con motivos vegetales de una altura de $55 \mathrm{~cm}$ (Arribas y Tarradell, 1987: 127). Para unos este edificio estaría ya desmontado a finales del siglo I (Equip d'Excavacions de Pollentia 1994b: 142). Para Partment, más que un templo este edificio se podría interpretar como la base original, dado su tamaño y ubicación, de la escultura ecuestre de bronce de

27 Referencias para Évora en Hauschild (1992 y 1994). El templo de Mérida catalogado como de culto imperial fue construido en pleno período tiberiano (Álvarez, 1992:90-91). 
medidas naturales hallada en las excavaciones de los años veinte y ya mencionada anteriormente ${ }^{28}$ (Partment, 1995: 43). Si ésa fuese su funcionalidad, la fecha de construcción estaría evidentemente asociada a la de la estatua, datada en el siglo I d.C. (A.A.V.V., 1990: 191). Cercano a él apareció una inscripción fragmentada de la que se puede leer lo siguiente (Arribas y Tarradell, 1987: 127): (A)VG LEG PRO PR F C/(P)RO LEG DEDICAVIT.

La interpretación dada a esta inscripción sería la de una dedicación a ese edificio por el gobernador provincial, actuando un legado de éste (Arribas y Tarradell, 1987: 131).

El Templete II, también de planta rectangular, mide $10,10 \mathrm{~m}$ en sentido Este-Oeste y aproximadamente unos 7,40 m Norte-Sur. Tiene una canal cortada en los bloques de piedra del borde del edificio en sus lados este y sur, sin trazas de su continuación por los otros dos lados. Podría tener una cella de 3 $\mathrm{m}$ y una pequeña pronaos de $1 \mathrm{~m}$. Se interpreta como un posible templo tetrástilo o dístilo in antis (Equip d'Excavacions de Pollentia 1994b: 142).

\section{EL FORO DE POLLENTIA EN EL SIGLO III D.C. (fig. 2)}

Los datos que se tienen del Foro de Pollentia en el siglo III d.C. son básicamente de tipo económico ya que proceden de las tabernae, tanto las que componen la ínsula de tabernas al oeste del foro, como los recintos 01 y 02 al norte del Capitolio pertenecientes a la insula al norte del foro. Durante este siglo III d.C. estas dos ínsulas estuvieron funcionando a pleno rendimiento hasta que un incendio acontecido sobre los años 270 y 280 destruyó toda la zona (Arribas y Tarradell, 1987: 133; Equip d'Excavacions de Pollentia 1994b: 142) ${ }^{29}$, perdiendo posiblemente esta área de la ciudad la condición de foro.

No se tienen datos claros de cuándo se llevó a cabo la reforma urbanística que dió a estas insulae de tabernas el aspecto que tuvieron durante el siglo III d.C., ahora bien, si extrapolamos los datos proporcionados por la excavación de los recintos 01 y 02 al norte de Capitolio, construidos en el siglo II d.C. (Equip d'excavacions de Pollentia 1994a: 220),

\footnotetext{
${ }^{28}$ Cf. supra circunstancias del hallazgo.

29 Fecha deducible por la gran cantidad de artefactos de finales del siglo III d.C., especialmente cerámicos (vajillas, principalmente formas Lamb. 40 y 42 de terra sigillata africana $C$, ánforas, cerámica de cocina, etc.), pero también numerario que Mattingly, en su estudio preliminar (Arribas y Tarradell, 1987: 133), clasifica como de Claudio II, acuñado en torno al año 280.
}

y sabiendo que funcionaban a la par que las tabernae de la insula al oeste del foro, se puede interpretar que ambas fueron reformadas en el siglo II d.C. Lo que sí queda claro es que el siglo III d.C. constituye la última fase de uso de estas tiendas y talleres, al ser destruidas por el ya mencionado incendio de fines del III d.C.

El aspecto de la insula al oeste del foro varió con esta reforma. Desde el exterior, uno de los cambios se llevó a cabo en los dos pórticos identificados, el de la fachada que da a la plaza del foro y el que estaba sobre la calle oeste (fig. 4). En ambos casos se construyen unos muros en los intercolumnios, para el caso de la fachada que da a la plaza del foro, y entre las pilastras en la fachada que da a la calle oeste. Nos encontramos ahora con un espacio muy cerrado desde el exterior donde se realizan transacciones económicas, ya que sólo se debía poder acceder al mismo desde sus esquinas. Podríamos clasificarlo realmente como un macellum, permitiéndonos compararlo con el aspecto de los zocos árabes, al menos en lo que se refiere a los lados este y oeste de esta ínsula. Conectados a estas reformas están unos bancos corridos construidos en la superficie del pórtico y adosados a las paredes de cada una de las tabernas conocidas hasta la actualidad.

Poco sabemos del aspecto que debía tener la fachada norte de esta ínsula debido a las alteraciones posteriores que sufrió esa zona al construirse sobre ella parte del lienzo de muro de un recinto fortificado datado en el siglo $v$ d.C. Menos aún del límite sur, al no haber concluido las excavaciones por ese lado de esta ínsula.

Por una parte se cambió el módulo de cada una de las habitaciones de las tabernas. Si lo comparamos con el de la época republicana, de forma rectangular, ahora pasará a una forma más cuadrada, aunque ninguna de las habitaciones hasta ahora identificadas repite la misma superficie. En la mayoría de las ocasiones se reutilizan como zócalos las paredes de fases anteriores. La técnica constructiva empleada en ese momento en las paredes es la siguiente: se realizan las primeras hiladas a base de piedras de tamaño pequeño entre las que se intercalan fragmentos de opus signinum y cerámica que puede alcanzar hasta $1 \mathrm{~m}$ de altura, a partir de las cuales se continuaba la pared con adobes ${ }^{30}$. La cubierta debió tener un entramado de madera dados los restos de vigas calcinadas recuperados en las excavaciones, soportando las tegulas e ímbrices. Se han recuperado de sus ventanas tanto fragmentos de

\footnotetext{
30 Se han identificado adobes fabricados con tierra rojiza y también adobes de tierra blanquecina (blanquet).
} 
vidrio como dos rejas de hierro, una en la Hab. F (Arribas y Tarradell, 1987: 132), y otra entre las Habitaciones X e Y. En ese momento las puertas de acceso, de madera, tienen un sistema de cierre que parece correspondería a puertas correderas al identificarse unas ranuras, como las de la Hab. Z, que tiene $10 \mathrm{~cm}$ de ancho por $276 \mathrm{~cm}$ de largo, con dos hendiduras equidistantes (fig.4). Este tipo de cierre se aprecia también en los accesos a las habitaciones A, J, V e Y.

Parece que estas tabernae, al menos durante el siglo III d.C., como ya se ha señalado en otra publicación (Arribas y Tarradell, 1987: 129), forman agrupaciones de dos en dos habitaciones. Desde la Hab. A se accede a F y desde J a M. Entre ellas tenían unos pasillos, en sentido Este/Oeste, a cada dos ámbitos de Norte/Sur, que debían usarse como callejones; nos referimos a los ámbitos identificados como Hab. B, Hab. N o al espacio entre las Hab. Y y Z, lugares a los que se les ha asignado también la funcionalidad de ser escaleras que dieran acceso al piso superior de las tabernas. Tienen acceso directo desde lo que fue el Pórtico al oeste del Foro las habitaciones A, J y O, y los callejones B y N. Desde lo que debió ser la Calle norte se accedía a las Hab. $\mathrm{P}$, con una subdivisión interna, $\mathrm{Q}$, que conecta por detrás con T y U. El acceso a las Hab. V, Y y Z se hacía desde el Pórtico de la Calle oeste. De todas estas habitaciones destaca la Hab. C, tanto por su tamaño, $7 \mathrm{~m}$ por $8 \mathrm{~m}$, como por el tipo de suelo, un pavimento de opus signinum con pequeñas placas de mármol, crustae, como si fuera un incipiente opus sectile; esta habitación ha sido interpretada como posible curia o santuario (Equip d'excavacions de Pollentia 1994b: 142). Si fuese ése el caso, esta funcionalidad se habría iniciado a partir de la reforma estructural que se llevó a cabo entre los siglos II y III d.C. La excavación de la Hab. B (fig. 6) ha identificado un muro en sentido norte/sur (UE5011) que va por debajo del pavimento de opus signinum de la Hab. $\mathrm{C}^{31}$, dividiendo el espacio anterior al siglo III d.C. en dos, como se ha descrito en el apartado de este escrito dedicado a la época republicana.

La funcionalidad de la mayoría de las tabernae como talleres o tiendas ha quedado demostrada por la serie de objetos y elementos recuperados en ellas sellados por el incendio de finales del siglo III d.C. En la Hab. J aparecieron una serie de pesas, cinco en total, de las que sólo una se repite en peso. La

\footnotetext{
.31 La cota a la que se encuentra este opus signinum de la Hab.C es la misma de los niveles del resto de tabernae donde se acumularon los escombros procedentes del incendio de finales del siglo III dC.
}

Hab. M está casi al completo ocupada por un pozo negro (Arribas y Tarradell, 1987: 129-30). Se han recuperado los fondos de dos dolia en la Hab. S y el Recinto 01. En la Hab. U se ha recuperado una caja de plomo con la representación en relieve de la cabeza de Medusa y, posiblemente, un toro. También se recuperaron aquí un balsamario de bronce en forma de busto de fauno, un anillo-sello con la inscripción «ACTIACI» y varias piezas redondeadas (rodelas) de vidrio opaco, con decoración incrustada, polícroma, en las que se han representando peces. Además de estos objetos, se encontraron otros de menor entidad como un vaso con una decoración incisa vegetal esquematizada, dos lucernas enteras, una de ellas con 5 picos, fragmentos de materia textil quemados, otras dos lucernas de disco, eslabones de una cadena y el gancho de una balanza. En la Hab. X, el almacén de la tienda identificada como Hab. Y, se han hallado diversas ánforas del siglo III d.C., como la forma Dressel 30, una magnífica pieza vidriada con forma de cratera con decoración en relieve e incisa, piezas de bronce en forma de sartén, etc. En la Hab. V se tiene suficientes indicios como para suponer que allí se fabricaba vidrio, mientras que en la parte más al norte existiría una serrería, dadas las sierras de hierro recuperadas (Arribas y Doenges, 1995).

No se puede saber si la insula al norte del Capitolio continuaba con mas tabernas a los lados este y oeste de los recintos 01 y 02 , aunque se intuye que sí.

\section{DEL SIGLO IV D.C. EN ADELANTE}

El incendio que destruyó las tabernas del foro a finales del siglo iII d.C. afectó a otros sectores de la ciudad como son la Casa de Polymnia o Ca'n Basser, por ejemplo (fig. 1). Estos datos unidos a la contrucción de un lienzo de muralla sobre una de las casas del barrio residencial de Sa Portella habían influido enormemente en una interpretación sobre el final de la ciudad hacia finales del siglo III d.C.

$\mathrm{Si}$ bien en principio se puede suponer que algún acontecimiento traumático sucedió a finales del siglo III d.C., que supuso una convulsión de la ciudad y posiblemente el final del foro como espacio público, no es menos cierto que la ciudad continuó habitada durante toda la antigüedad tardía (Orfila, Riera, Cau y Arribas, en prensa), aunque por el momento sea difícil calibrar la intensidad de uso de la ciudad en fechas tan avanzadas.

En el área del foro (fig. 2), sobre los escombros acumulados del incendio del siglo III d.C., se obser- 


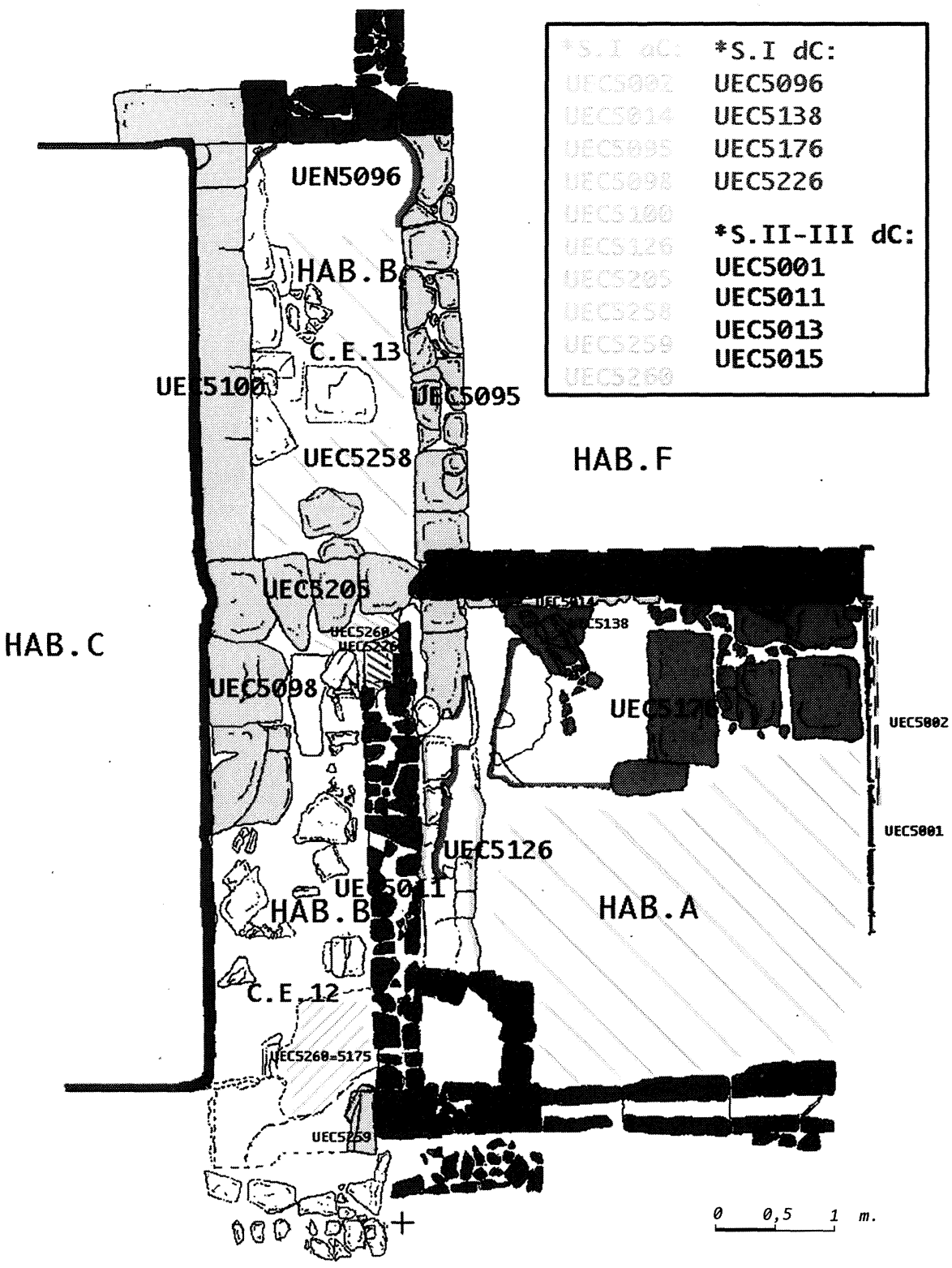

Fig. 7.-Insula de tabernas al oeste del foro. Habitaciones A, B, C y F con indicaciones de las diversas fases constructivas.

van, por una parte, una serie de pavimentos de opus signinum, y,por otra, al norte de la insula de tabernas al oeste del foro y del propio Capitolio (fig. 7) se ha localizado una estructura defensiva tardía que ha sido ya descrita en detalle con anterioridad (Orfila, Riera, Cau y Arribas, en prensa).

Del recinto fortificado se ha identificado hasta la fecha un tramo de su lienzo norte, de unos $20 \mathrm{~m}$, que incluye en su cara norte una torre rectangular maciza de 4,80 m en su lado septentrional y 3,20 en sus lados este y oeste.
Parte del lienzo de este complejo defensivo había sido ya descubierto en las intervenciones efectuadas a finales de los años ochenta, cuando se localizó una estructura que no se había podido identificar con claridad pero que parecía pertenecer a una muralla (Equip d'excavacions de Pollentia, 1994a). En fechas recientes, las campañas de excavación centradas en este recinto han permitido confirmar que las estructuras recuperadas forman parte de un gran complejo defensivo que se ha denominado Complejo Estructural 14 (fig. 8), compuesto por 


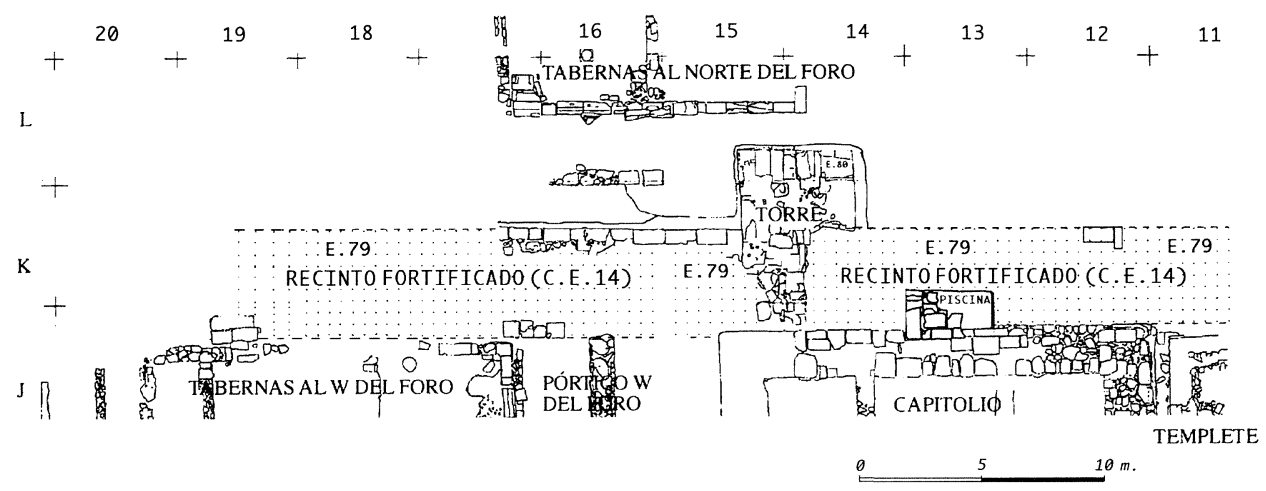

Fig. 9.-Plano del recinto fortificado tardío al norte del foro.

un tramo de muralla (Estructura 79) y una torre (Estructura 80). Hasta el momento, el tramo del que se dispone discurre en sentido Este/Oeste, desde la parte norte del Capitolio, pasando por el norte del pórtico oeste del foro, hasta el norte de la insula de tabernas al oeste del foro.

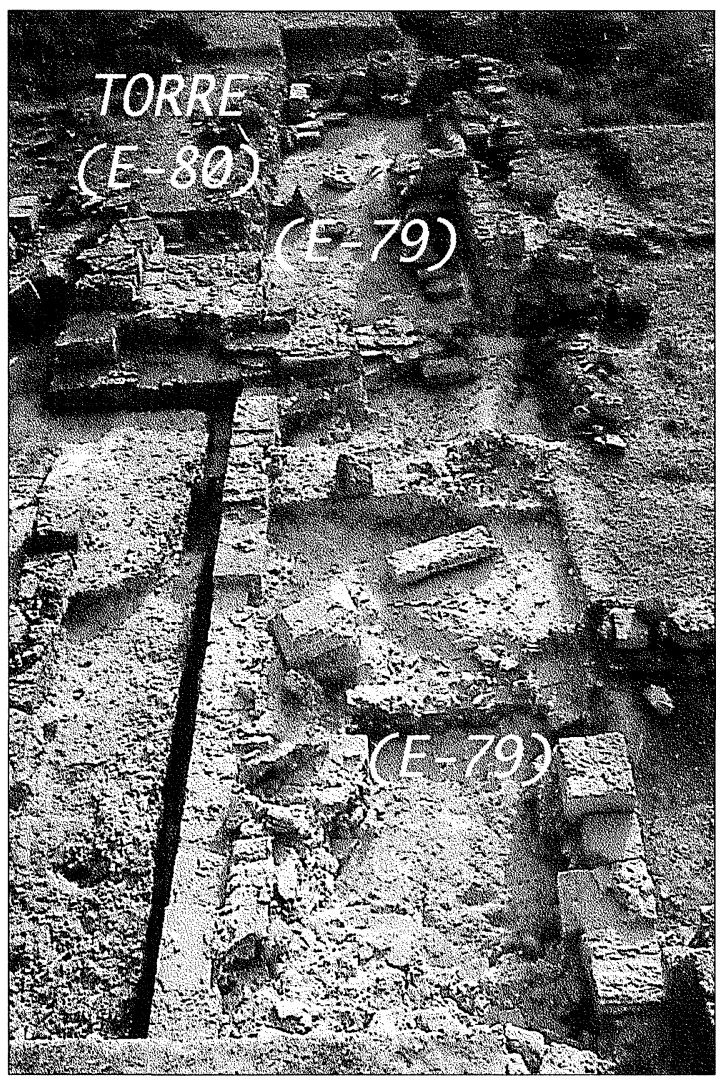

Fig. 8.-Lienzo de muralla del recinto fortificado tardío al norte del foro, apreciándose en primer término parte del muro (Complejo Estructural 79) y a la izquierda de la foto la torre cuadrada (Complejo Estructural 80) adosada al norte del muro.
La anchura de este lienzo de muralla (E.79, fig. 9) es de 4,46 m y consta de un muro de doble paramento con relleno interno de piedras y elementos de construcción. La pared norte de la muralla (UE5216), que corresponde a la cara externa de esta construcción defensiva, no reutiliza estructuras anteriores y está formada por bloques de piedra bien escuadrados ligados con argamasa rica en cal y nivelados mediante fragmentos de cerámica. Esta pared descansa sobre una banqueta de cimentación (UE5305) que, junto con la primera hilada, se asientan en la trinchera de fundación (UE5319).

La pared sur, cara interna de la muralla, está perdida en diversos tramos, si bien los tramos que se conservan permiten observar ciertas diferencias constructivas. El primer tramo reconocible (UE5255), ubicado frente al pórtico oeste del foro, presenta características similares a las de la pared norte. Por contra, los tramos identificados al norte del Capitolio y al norte de las tabernas reutilizan estructuras de edificaciones anteriores. De esta forma, la cara norte de las tabernas se convierte en parte del lienzo interno de la muralla, mientras que hacia levante los restos del muro norte del Capitolio pasan también a formar parte de la cara interna de la muralla.

Las caras internas de cada una de las paredes descritas presentan refuerzos estructurales a base de acumulaciones de piedras y argamasa. El interior de la muralla, cuando es original, está compuesto por capas de piedras que tienen entre medias unas coladas de una argamasa poco compactada de cal, y presenta, además, rellenos con gran cantidad de cascajo y tierra muy arenosa, así como elementos de edificaciones anteriores.

La trinchera de fundación de esta estructura defensiva ha sido localizada sólo en la cara externa de la pared norte (UE5216) y circundando la torre. En el interior de la trinchera (UE5319) fue colocada 


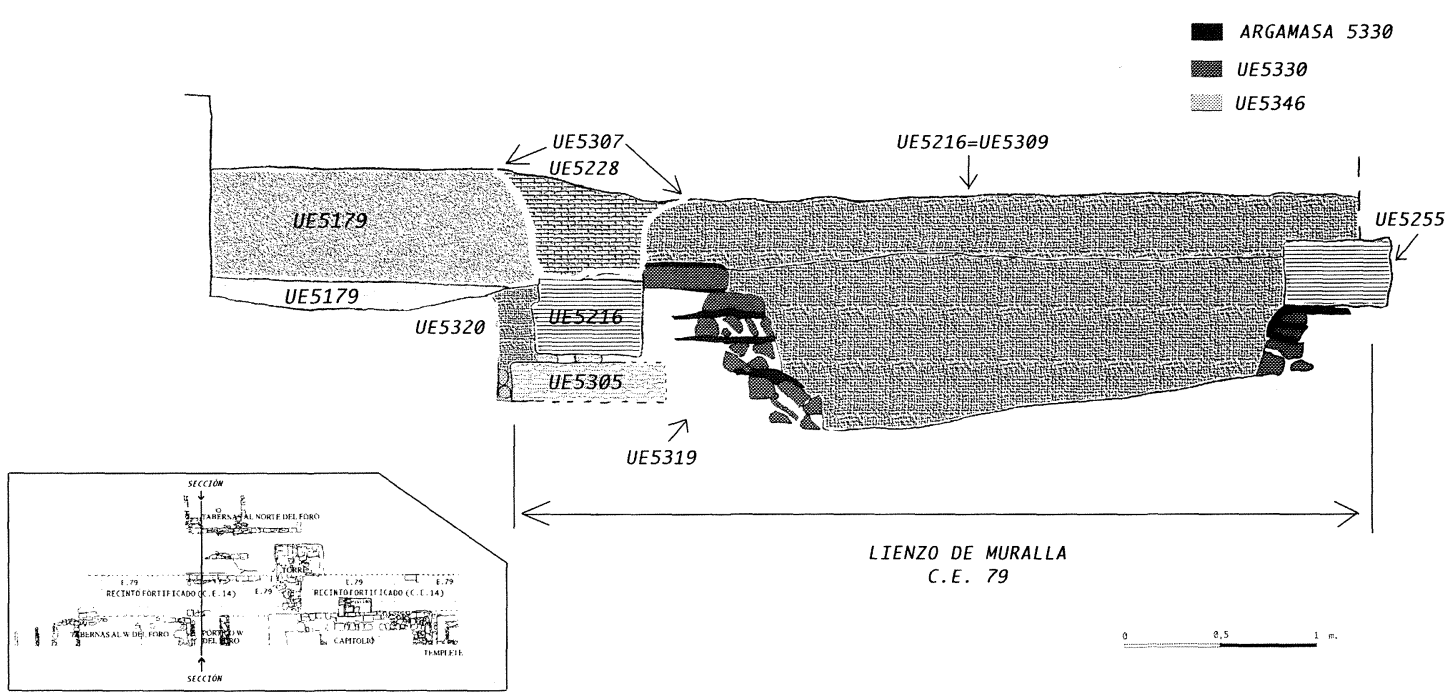

Fig. 10.-Sección del recinto fortificado tardío al norte del foro.

una primera hilada de bloques a modo de banqueta (UE5305), sobre la que se asientan la pared norte de la muralla (UE5216) y la torre. El relleno de la trinchera (UE5320) está compuesto por tierra y piedras, materiales de construcción y escasos fragmentos cerámicos.

La datación de esta estructura defensiva es problemática. Hasta la campaña de 1998 la datación se basaba en la recuperación de una inscripción funeraria ${ }^{32}$ en principio del siglo III d.C., formando parte de los primeros metros de la pared norte (UE5216) de la E.79, reaprovechada como tantas otras piezas que forman parte de esta estructura defensiva, marcando, por tanto un terminus post quem en ese siglo.

Las trincheras de fundación excavadas hasta el momento han proporcionado pocos materiales, pero la presencia de algunos fragmentos de terra sigillata africana $\mathrm{D}$ en el relleno de la trinchera de fundación (UE5320) permite proponer ahora un terminus post quem del siglo Iv d.C. Es probable además que la presencia de un fragmento de un posible Hayes 91 con listel atrofiado y cerámicas de cocina moscovíticas permitan llevar esta cronología hasta el siglo v d.C. avanzado, si bien los datos de los que se disponen son todavía muy escasos (Cau, 1993 y 1998, Cau et alii, en prensa).

Por encima de esta estructura parece extenderse la que ha sido considerada como necrópolis altomedieval del foro. De hecho una de sus tumbas está

${ }^{32}$ Localizada en las excavaciones de los años ochenta con el n. registro. P.89.18-110: D M/ SEX R O CVAE/ VIX AN XXCIIII/ FI ARCHIPPIANVS/ RI PIISSIMAE/ AENDATISSIM. recortada sobre uno de los sillares de la torre indicando que la necrópolis del foro es posterior al recinto fortificado tardío, y que la torre de esta edificación defensiva debía estar prácticamente arrasada cuando este espacio fué utilizado como cementerio, ya que tan sólo conservaba una altura máxima de $1,50 \mathrm{~m}$ cuando la tumba fue recortada.

La localización de esta construcción defensiva en el área del antiguo foro significa una clara reducción del área fortificada en relación a la de $\mathrm{Sa}$ Portella, datada en el siglo III d.C., pero no supone un abandono del resto del solar urbano, tal y como demuestran los materiales tardíos hallados en la Casa de los dos Tesoros y en la Casa de la Cabeza de Bronce, por ejemplo. De esta forma, parece plausible proponer, como hipótesis a contrastar, que el complejo estructural localizado en el foro corresponda a una fortificación tardía de la parte alta de la ciudad, coincidiendo con la topografía más elevada del solar urbano, sin que ello suponga el abandono de la ciudad extramuros.

La fecha de construcción de la estructura permite indicar que estamos frente a la última gran reforma edilicia del área del antiguo foro. No podemos olvidar además, que la presencia de cerámicas, especialmente de cocina, fechables claramente en época bizantina (Laiz y Ruiz, 1988; Ramallo, Ruiz y Berrocal, 1996; Cau, 1996 y 1998), atestigua la frecuentación de esta zona en estos momentos, aunque no pueda establecerse una relación directa con la estructura localizada.

En general, puede afirmarse que las últimas fases de la vida de Pollentia no parecen haber sido tan catastróficas como se había sostenido tradicionalmente 
por influencia de las fuentes escritas. El espacio urbano sigue habitado tras la conquista vándala del 455 d.C. y tras la conquista bizantina del 534 d.C. De hecho es incluso tentador relacionar la fortificación tardía del foro con la política de construcción de fortificaciones impulsada por Justiniano, aunque bien es cierto que por el momento no hay ni un solo dato objetivo para sostener una tal afirmación.

La presencia de cerámicas de época vándala y bizantina en el foro y en otros puntos de la ciudad es un hecho plenamente constatado (Arribas, Tarradel y Woods, 1973 y 1978; Martín, 1983; Cau, 1993; Reynolds, 1995; Gumà, Riera y Torres, 1998; Orfila, Riera, Cau y Arribas, en prensa). Las cerámicas permiten una datación clara hasta mediados del siglo vII d.C., fecha hasta la que se pueden rastrear fácilmente las producciones africanas. El siglo VIII y el IX son prácticamente desconocidos tanto desde un punto de vista de la cultura material como estructural. Sin embargo, hay que constatar la excepcional pieza de cerámica de vetrina pesante hallada en el foro que puede datarse en el siglo IX (Rosselló, 1982; Gumà, Riera y Torres, 1996; Rosselló y Coll, 1997).

A inicios del siglo x Mallorca fue conquistada por los musulmanes. La ciudad de Pollentia continúa aún habitada y en la zona del antiguo foro se han localizado cerámicas islámicas que permiten señalar la presencia de población hasta época almohade, si bien parece que la ciudad fue abandonada antes de la conquista cristiana de la isla en el 1229.

\section{BIBLIOGRAFÍA}

A.A.V.V., 1990: Los bronces romanos en España, Ministerio de Cultura, Madrid.

Álvarez Martínez, J. M., 1992: El templo de Diana, Cuadernos de arquitectura romana, 1, p.8393, Murcia, 1992.

Amorós, L. R.; Almagro, M.; Arribas, A., 1953: Excavaciones del teatro romano de Pollentia, $A r$ chivo Español de Arqueología, XXVI, p.281300.

Arribas, A., 1978: La Arqueología de Pollentia, en Tarradell, M.; Arribas, A.; Rosselló, G., Historia de Alcúdia, tomo I, p.111-291, Mallorca.

Arribas, A., 1983a: Pollentia: Problemas de topografía y conservación de la ciudad, Symposium de arqueología. Pollentia y la romanización de las Baleares 1977, p.35-46, Alcúdia, Mallorca.

Arribas, A. (Ed.), 1983b: Pollentia. Estudio de los materiales I. The William L. Bryant Foundation 3. Palma.
Arribas, A., 1983c: La romanització de les Illes Balears. Lliçó inaugural del curs 1983-84, Palma de Mallorca.

Arribas, A., Doenges, N. A., 1995: Piezas singulares de una estancia del área del foro de Pollentia, $1^{\circ}$ Congreso de Arqueología Peninsular, Actas V, Trabalhos de Antropologia e Etnologia, vol. 35 (1), p.397-420, Porto.

ArRibas, A., Llabrés, J., 1983: Una necrópolis romana en el Ager Pollentino, pp. 303-365, Pollentia. Estudio de los materiales, I. Sa Portella, excavaciones 1957-1963. Palma.

Arribas, A.; Tarradell, M., 1987: El foro de Pollentia. Noticia de las primeras investigaciones, Los foros romanos de las Provincias Occidentales, p.121-136, Madrid.

Arribas, A.; Tarradell, M.; Woods, D., 1973: Pollentia I. Excavaciones en Sa Portella. Alcúdia (Mallorca), Excavaciones Arqueológicas en España, $n^{\circ} 75$. Madrid.

Arribas, A.; Tarradell, M.; Woods, D., 1978: Pollentia II. Excavaciones en Sa Portella. Alcúdia (Mallorca), Excavaciones Arqueológicas en España, $n^{\circ}$ 98. Madrid.

BAlIL, A., 1965: Notas sobre las Baleares romanas. IX Congreso Nacional de Arqueología, pp.309310. Valladolid.

Beltrán, A., 1983: La vida de Pollentia según la epigrafía, en Symposium de Arqueología. Pollentia y la Romanización de las Baleares, pp. 4754, Mallorca.

Bendala, M., 1990: El plan urbanístico de Augusto en Hispania: Precedentes y pautas macroterritoriales, en Trillmich, W.; Zanker, P., Stadtbild und Ideologie, pp.25-42, München.

CAU, M.A., 1993: Las cerámicas tardorromanas de cocina modeladas a mano o a torno lento de Sa Mesquida, Sta. Ponça (Calvià, Mallorca: Caracterización macroscópica, caracterización arqueométrica y estudio arqueológico. Una Propuesta metodológica. Febrero 1993, Departamento de Prehistoria, Historia Antigua y Arqueología de la Universidad de Barcelona.

CAU, M.A., 1994: Una fábrica importada de cerámica tardorromana de cocina, Trabalhos de Antropologia e Etnologia, vol.XXXIV, Porto, pp.391417.

CAU, M.A., 1996: Cerámicas tardorromanas de cocina con inclusiones de rocas metamórficas halladas en las Islas Baleares: ¿posibles producciones de la zona de Cartagena?, Actes du Colloque de Perigaux, suppl. a la Revue d'Archéometrie, pp.101-106.

CAU, M.A., 1998: Cerámicas tardorromanas de co- 
cina de las Islas Baleares: estudio arqueométrico, Col.lecció de Tesis Microfitxades, Universitat de Barcelona.

Cau, M. A.; Cardell, J.; Orfila, M., (Eds.), (en prensa): Sa Mesquida. El llegat de Roma, Calvià, Mallorca.

Cau, M. A.; J.; Orfila, M.; Riera, M., Els darrers segles de Pol.lentia, I Jornades d'Estudis Locals. Alcudia 13-14 de novembre 1998, Mallorca

Cardell, J.; Orfila, M., 1991-2: Posible catastro romano en la isla de Mallorca, Cuadernos de Prehistoria y Arqueología 16-17, p.415-423, Universidad de Granada.

Coll, J.; Mazaira, L.; Riutort, S., 1984: Evolución del hábitat durante la Prehistoria y la Antigüedad en el término municipal de Alcudia, Arqueología Espacial 2. Teruel, p.111-129.

Equip D'excavacions de Pollentia, 1993: Un conjunt de materials d'època tardo-republicana de la ciutat romana de Pollentia (Alcudia, Mallorca), Pyrenae 24, pp. 227-267, Barcelona.

Equip D'excavacions de Pollentia, 1994a: Resultats dels treballs d'excavació a l'àrea central de la ciutat romana de Pollentia (Alcudia, Mallorca): avanç preliminar, Pyrenae 25, pp. 215-224, Barcelona.

EquiP D'excavacions de Pollentia, 1994b: Avanç dels resultats dels treballs d'excavació a l'àrea central de la ciutat romana de Pol.lentia, XIV Congreso Internacional de Arqueología Clásica. La ciudad en el mundo romano, vol. 2, pp. 140142, Tarragona.

Fernández-Miranda, M., 1983: Pollentia (Mallorca). Las cerámicas talayóticas procedentes de la calle Porticada. A. Arribas Ed., Pollentia. Estudio de los materiales I. The William L. Bryant Foundation 3, pp.11-45. Palma.

Gros, P.; Torelli, M., 1992: Storia dell'urbanistica. Il mondo romano. Editori Laterza, $2^{\circ}$ Edición 1992 (1 1988), Bari.

GumÀ, M.M; Riera, M.M.; Torres, F., 1998: Contextos ceràmics dels segles IV-X a l'illa de Mallorca, en Contextos ceràmics d'època romana tardana $i$ de l'alta edat mitjana (segles $I V-X$ ), Arqueomediterrània, 2, Universitat de Barcelona, pp.249-268.

Hauschild, Th., 1992: El templo romano de Évora, en Templos romanos de Hispania, Cuadernos de arquitectura romana, 1, pp.107-118, Murcia.

Hauschild, TH., 1994: El templo romano de Évora, nuevas investigaciones, Actas del XIV Congreso Internacional de Arqueología Clásica. La ciudad en el mundo romano, vol. 2, pp.197-200, Tarragona.
Laiz, M.D.; RuIZ, E., 1988: Cerámicas de cocina de los siglos V-VII en Cartagena (c/.Orcel-D.Gil), Antigüedad y Cristianismo, V, pp.265-301.

LlABRÉs, J; IsAsI, R., 1934: Excavaciones en los terrenos donde estuvo enclavada la ciudad romana de Pollentia (Baleares, isla de Mallorca). Memoria de los trabajos practicados en 1930-31, Memoria de la Junta Superior del Tesoro Artístico 131, Madrid.

MAROT, T., 1990: Monedes vándales i bizantines a Pollentia, Gaceta Numismatica 99, IV-90, p.2933, Barcelona.

MAROT, T., 1997: Aproximación a la circulación monetaria en la Península Ibérica y las islas Baleares durante los siglos V y VI: la incidencia de las emisiones vándalas y bizantinas, Revue Numismatique, vol 152, pp.157-190, Paris.

Martin, G., 1983: Terra Sigillata Clara de Pollentia, en Arribas, A. (Ed.), Pollentia. Estudio de los materiales, I. Sa Portella, excavaciones 19571963, The William L. Bryant Foundation 3, pp.167-240, Palma de Mallorca.

Mattingly, H., 1983: Roman Pollentia: coinage and history. A. Arribas Eds., Pollentia. Estudio de los materiales $I$. The William L. Bryant Foundation 3, pp.243-301, Palma de Mallorca.

MAYer, M.; RodÀ, I., 1983: Consideraciones sobre el topónimo Pollentia y el asentamiento romano en la bahía de Pollensa, Symposium de Arqueología. Pollentia y la Romanización de las Baleares, pp.23-34, Mallorca.

Merino, J. 1994: La sortida de materials arqueològics de Pollentia envers al Museo Arqueológico Nacional, III Congrés El nostre patrimoni cultural: el patrimoni tudat (1836-1994), pp.39-50, Mallorca.

Merino, J., 1999: Les excavacions arqueològiques de Gabriel Llabrés Quintana a Pol.lentia, I Jornades d'Estudis Locals. Alcudia 13-14 de novembre 1998, pp.39-50, Alcudia, Mallorca.

MOREL, J-P., 1981: La céramique campanienne: les formes. Bibliothèque des Ecoles Françaises d'Athènes et de Rome. Roma.

OrfilA, M. 1988: La necrópolis de Sa Carrotja y la romanización del Sur de la isla de Mallorca. British Archaeologicals Reports, International Series 397. Oxford

ORFILA, M. (en prensa): La vajilla de barniz negro y la ciudad romana de Pollentia, (Alcudia, Mallorca), La ceramique de vernis negre del segle II $i$ I avanç de Crist: centres productors mediterranis i comercializació a la Peninsula Ibèrique. Taula Rodona celebrada a Ampuries 4-5 de juny 1998. 
Orfila, M.; ArRibas, A., 1997: La ciudad romana de Pollentia (Alcudia, Mallorca) en la actualidad. Congreso ciudades históricas vivas. Ciudades del pasado: pervivencia y desarrollo, Mérida 1997, p.63-67.

Orfila, M.; Arribas, A., Doenges, N. A., 1999: El forum de la ciutat romana de Pollentia, estat actual de les excavacions, I Jornades d'Estudis Locals, noviembre de 1998, pp.85-100, Al-cudia.

Orfila, M.; Riera, M.; CaU, M.A.; Arribas, A., (en prensa): Aproximación a la topografía urbana tardía de Pollentia (Mallorca): Construcciones defensivas, IV Reunió d'Arqueologia Cristiana Hispánica, Cartagena, 1998.

Palanques, M. L., 1992: Las lucernas de Pollentia, The William Bryant Foundation, Palma de Mallorca, 1992.

Partment, T. W., 1995: The Capitolium of Pollentia. Dartmouth College, N.H. Trabajo dactilografiado.

Piganiol, A. 1962: Les documents cadastraux de la colonie romaine d'Orange, Gallia supl. 16, p.80 y ss, Paris.

Ramallo, S.; Ruiz, E.; Berrocal, M. C., 1996: Contextos cerámicos de los siglos V-VII en Cartagena, AEspA vol.69, pp.135-189, Madrid.

RAmón, J., 1985: Els monuments antics de les illes Pitiüses. Conselleria de Cultura. Eivissa.
Reynols, P., 1995: Trade in the Western Mediterranean, AD 400-700: The ceramic evidence, BAR International Series, 604.

Roldán, J. M. 1978: Historia de España Antigua. Ed. Cátedra. Madrid

Rosselló BoRdoy, G., 1982: El portaviandas medieval de Pollentia (Alcudia/Mallorca), Boletín de la Sociedad Arqueológica Luliana, 39, pp. 1982.

Rosselló Bordoy, G.; Coll, B., 1997: Cerámica popular mallorquina. Col. El Disseny A. L'Artesania Balear, vol. 3, Palma de Mallorca.

Sanmartí, J.; Principal, J.; Trias, GL.; Orfila, M., 1996: Les ceràmiques de vernís negre de Pollentia. The William L. Bryant Foundation 5, Barcelona, 1996

SubíAs, E., 1994: Anàlisi metrològica del capitoli, Equip d'excavacions de Pollentia, 1994a: Resultats dels treballs d'excavació a l'àrea central de la ciutat romana de Pollentia (Alcudia, Mallorca): avanç preliminar. Pyrenae 25, pp. 220224.

Tarradell, M., 1978: Pollentia. Esquema de una aproximación histórica, en Tarradell, M.; Arribas, A.; Rosselló Bordoy, G., Historia de Alcudia, tomo I, Mallorca.

ZuccA, R., 1998: Insulae Baliares. Le isole Baleari dotto dominio romano. Cariocci Editore, Roma. 